IZA DP No. 7414

The Paradox of Redistribution Revisited: And That It May Rest in Peace?

Ive Marx

Lina Salanauskaite

Gerlinde Verbist

May 2013 


\title{
The Paradox of Redistribution Revisited: And That It May Rest in Peace?
}

\author{
Ive Marx \\ CSB, University of Antwerp \\ and IZA \\ Lina Salanauskaite \\ CSB, University of Antwerp \\ Gerlinde Verbist \\ CSB, University of Antwerp
}

Discussion Paper No. 7414
May 2013

IZA

P.O. Box 7240

53072 Bonn

Germany

Phone: +49-228-3894-0

Fax: +49-228-3894-180

E-mail: iza@iza.org

\begin{abstract}
Any opinions expressed here are those of the author(s) and not those of IZA. Research published in this series may include views on policy, but the institute itself takes no institutional policy positions. The IZA research network is committed to the IZA Guiding Principles of Research Integrity.

The Institute for the Study of Labor (IZA) in Bonn is a local and virtual international research center and a place of communication between science, politics and business. IZA is an independent nonprofit organization supported by Deutsche Post Foundation. The center is associated with the University of Bonn and offers a stimulating research environment through its international network, workshops and conferences, data service, project support, research visits and doctoral program. IZA engages in (i) original and internationally competitive research in all fields of labor economics, (ii) development of policy concepts, and (iii) dissemination of research results and concepts to the interested public.
\end{abstract}

IZA Discussion Papers often represent preliminary work and are circulated to encourage discussion. Citation of such a paper should account for its provisional character. A revised version may be available directly from the author. 


\section{ABSTRACT}

\section{The Paradox of Redistribution Revisited: And That It May Rest in Peace?}

There is a long-standing controversy over the question of whether targeting social transfers towards the bottom part of the income distribution actually enhances or weakens their redistributive impact. Korpi and Palme have influentially claimed that "the more we target benefits at the poor, the less likely we are to reduce poverty and inequality". The basic empirical underpinning of this claim is a strong inverse relationship at the country level between social transfer targeting and redistributive impact. We show that this no longer holds as a robust empirical generalisation. The relationship between the extent of targeting and redistributive impact over a broad set of empirical specifications, country selections and data sources has in fact become a very weak one. For what it matters, targeting tends to be associated with higher levels of redistribution, especially when overall effort in terms of spending is high. We try to make substantive sense of this breakdown of the originally established relationship by focusing on two questions: first, what has changed in the countries originally included in the study and, second, what is different about the countries now additionally included in the analysis?

JEL Classification: $\mathrm{H} 1, \mathrm{H} 2, \mathrm{H} 53$

Keywords: targeting, tax benefit policies, redistribution, inequality

Corresponding author:

Ive Marx

Herman Deleeck Centre for Social Policy

University of Antwerp

Sint-Jacobstraat 2

2000 Antwerp

Belgium

E-mail: ive.marx@ua.ac.be

\footnotetext{
* This study is part of the EU FP7 Funded GINI project (http://www.gini-research.org). We are very grateful for the support of many individuals and institutions. In particular, our thanks go to Lane Kenworthy for providing us with the code used in his own study and thus facilitating the starting point of this analysis. Earlier versions of this paper have benefitted from comments during presentations at the FISS Conference (June, 2012), the IARIW Conference (August, 2012), and several seminars. We particularly thank Joakim Palme for comments.
} 


\section{Introduction}

There is a long-standing controversy in the academic literature over the question of whether targeting benefits towards the bottom part of the income distribution actually enhances or weakens their redistributive impact. Korpi and Palme have influentially claimed that "the more we target benefits at the poor, the less likely we are to reduce poverty and inequality". The basic empirical underpinning of this claim is a strong inverse relationship at the country level between social transfer targeting and redistributive impact.

This paper shows that this key finding no longer holds as a robust empirical generalisation. The relationship between the extent of targeting and redistributive impact over a broad set of empirical specifications, country selections and data sources has in fact become a very weak one, suggesting that the extent of targeting per se may not matter anymore as much as we have assumed since Korpi and Palme.

Clearly, this issue is actually of more than academic importance. In its 2011 report on inequality "Divided We Stand", the OECD calls for "well-targeted income support policies", however without clearly specifying what form and strength this should take. By the same token, the European Commission (2013) has launched a 'Social Investment Package' also calling for better targeting and conditionality: "Support should be better targeted to those in need at the times they need it”. Organisations like the IMF and the World Bank have long advocated targeted benefits, specifically in the form of means-tested social safety nets. The coming years will be marked by continued budget austerity in many countries. In the context of rising demands on welfare systems, the issue of targeting is likely to become even more relevant.

This paper proceeds as follows. We first summarize the story so far, devoting considerable attention to the original Korpi and Palme thesis. We then discuss the more recent literature, most notably recent re-examinations suggesting that targeting may not be so bad after all. We contextualize the discussion about the particular link between targeting and redistribution in the broader puzzle of egalitarianism. After discussing methodological and measurement issues we move on to the empirical part, first presenting the main results and then robustness of these results for variations in measurement and data. In the discussion part we try to make sense of the results, focusing on two questions: a) what has changed in the countries originally included in the study; b) what is different about the countries now additionally included in the analysis? In a final section we conclude and set out some directions for further research.

\section{The story so far: the paradox of redistribution}

'The Paradox of Redistribution and Strategies of Equality: Welfare State Institutions, Inequality and Poverty in the Western Countries', an influential article by Walter Korpi and Joakim Palme published in the American Sociological Review (ASR) in 1998 marked a seminal point in a long-standing controversy in welfare state literature over the question whether targeting actually benefits the redistributive impact of welfare state policies, especially social transfers.

Diametrically opposed views still exist on this issue. On the one side there are those who belief that a welfare state can only fight poverty effectively and efficiently (i.e. cost- 
effectively) when benefits are mainly targeted to those most in need, i.e. when benefits are selective. Goodin and Le Grand (1987: 215): "the beneficial involvement of the non-poor in the welfare state is not merely wasteful - it is actually counterproductive. The more the nonpoor benefit, the less redistributive the impact of the welfare state will be.”

Economists have moreover claimed that the budgetary return to targeting also entails an economic advantage. Lower public expenditures, after all, imply lower taxes, which in turn are supposed to be conducive to economic growth. Economic growth, the argument proceeds, benefits the poor directly (although not necessarily proportionally so) and increases at the same time the fiscal base for redistributive policies.

This view of selectivity has never been commonly shared. Two sorts of arguments underpin this more critical stance.

First, there are technical considerations. Van Oorschot (2002) sums up the most important dysfunctions of means-testing. First, these include higher administrative costs. Establishing need or other relevant criteria require monitoring, whereas universal benefits allow for less complex eligibility procedures. Furthermore, means tested benefits are subject to higher nontake up, partly because of stigmatization issues. Finally, targeted benefits can give rise to socalled dependency traps, where benefit recipients have little incentive to take up work or increase working hours because this would entail loss of benefits.

A second line of counter-argument is that proponents of selectivity pursue a 'mechanical' economic argument which makes abstraction of the political processes which determine how much is actually available for redistribution. The reasoning is that, paradoxically, in countries with selective welfare systems less resources tend to be available for redistribution because there is less widespread and less robust political support for redistribution. As a consequence, the redistributive impact of such systems tends to be smaller. To put it another way: some degree of redistributive "inefficiency" (the Matthew-effect) is said to foster wider and more robust political support for redistribution, including to the most needy. This follows from the fact that a universal welfare state creates a structural coalition of interests between the least well-off and the politically more powerful middle classes (median voter theorem). By contrast, a selective system entails an inherent conflict between the least well-off, by definition the sole recipients of social transfers, and the better off, who fund the system without the prospect of getting much out of it.

The juxtaposition outlined above forms the starting point for Korpi and Palme. In their 1998 article, they employ a somewhat more complex typology, but their classification of welfare states is essentially based on the dimension universalism versus selectivity. Based on data relating to institutional characteristics of welfare states on the one hand, and data relating to observed income distributions and financial poverty on the other, they conclude that more selective systems, paradoxically, have a smaller redistributive impact than universal systems offering both minimum income protection as well as income security and cost compensations (for children) in a broader sense. Korpi and Palme find that this relationship is mediated by the relative size of available means for redistribution. In essence, selective systems are generally smaller systems, and for that reason less redistributive, despite their design to that effect. To be fair, Korpi and Palme do not go as far as saying that the more universal system are the more redistributive they will be. But they do say that strong targeting implies weak redistributive outcomes. 
Korpi and Palme's main conclusion went relatively uncontested for a while although some scholars expressed reservations because of the rather rudimentary character of the research methods (Bergh 2005). The degree of redistribution, for example, is measured by comparing the actually observed income inequality or at-risk-of-poverty rate with a rather unsophisticated 'counterfactual' distribution. In theory this counterfactual ought to accurately reflect the income distribution that would prevail in the absence of social transfers. However, the construction of this counterfactual is hampered by theoretical and practical problems. In most cases, including in Korpi and Palme's paper, pre-transfer income is simply calculated by deducting observed social transfers and re-adding observed taxes. Full abstraction is thus made of any behavioural effects which a change in tranfer/tax regime would entail. While patently less than perfect, the reality is that no satisfactory method exists to adequately model such behavioural effects, except for very specific measures and marginal deviations.

Another critique was formulated by Moene and Wallerstein (2001; 2002) who argued that analyses of redistribution need to be done at a more disaggregated level than 'the welfare system' because the determining redistributive principles may differ substantially for, say, unemployment, health care or pensions. Some schemes may rest heavily on the insurance principle, while others may put more weight to the need-principle. Thus universality and selectivity can coexist within one system. Yet Moene and Wallerstein (2001; 2002) also conclude that universal provisions provoke the largest political support because of the higher chance of middle class citizens to become a beneficiary. Some opinion based studies also confirm that universal welfare schemes enjoy broader support (Forma, 1997; Kangas, 1995) and that universal schemes are more politically robust in times of austerity (Nelson, 2007; Ferrarini, Nelson and Höög, 2013). It is plausible, however, that public opinion is influenced by the institutional set-up of a welfare state and so the causality cannot be seen as running one way (see Larsen, 2008; McCarthy and Pontusson, 2009). Also, one should not overestimate the effect of public opinion on social policy (e.g. Brooks and Manza, 2006), as public policy is also influenced by resource mobilization, path dependence, political framing etc. There is other evidence in support of universalism, for example on the basis of studies that look at particular programmes. Corak, Lietz and Sutherland (2005) - in a study based on incomes at the end of 1990's or beginning of 2000's - for example find that universal child related benefits - not those targeted at the poorest - provide better protection against poverty. Their conclusion that 'targeting within universalism', in Skocpol's (1991) words, yields the best outcomes is echoed by Van Mechelen and Bradshaw (2013), Van Lancker et al. (2012), Figari et al., 2011. Brady et al. (2012), however, conclude in favour of universalism if it comes to anti-poverty policies for single mothers.

Returning to focus of this paper, some recent studies have claimed that the cross-country relationship between overall targeting and obserserved redistributive impact has weakened, or even reversed over time. Kenworthy (2011) reproduces and updates Korpi and Palme's analyses, which related to the situation in 11 countries as of 1985 . Kenworthy's findings confirm that countries with more universal benefits achieve more redistribution (measured in the size of redistributive policies in the budget) for the period 1980 to 1990. By 1995, the image becomes less clear. Data for 2000 and 2005 seem to indicate that there is no longer any association (either positive or negative) between the two variables. Evidently, the findings are based on a small number of cases (10 countries), which make them particularly sensitive to outliers. A trend towards more targeting in Denmark, in conjunction with an evolution towards more universal benefits in the US, is largely responsible for the shift in conclusions. Moreover, the new findings may be driven to some extent by the growing share of pensions in social spending. However, analyses on an alternative dataset, controlling for pensions and 
featuring a larger number of countries, suggest that as of the mid 2000s, universalism is negatively associated with redistribution.

Kenworthy refers here to an earlier study by Whiteford which shows that ranking method matters, a more than technical measurement issue to which we return in this paper. In the studies by Korpi and Palme and, as it is said to be a replication, Kenworthy, the calculations to establish the degree of targeting are based on households' position in the income distribution before taxes and after transfers (i.e. gross income). Whiteford uses post tax/transfer income, i.e. disposable income, as the ranking measure. We return to the issue of the ranking income concept in the section on "Measuring targeting and redistribution", and will test the sensitivity of the results for using different ranking income concepts. Whiteford finds that universalism correlates negatively with redistribution. Kenworthy writes about this: "This by no means settles the question, but it does suggest additional reason to rethink the notion that targeting is an impediment to effective redistribution" (Kenworty, 2011:58). This paper takes the quest further from there, addressing measurement issues in more depth, expanding the number of countries included in the analysis and checking for robustness against selected methodological choices, such as data source or income concepts.

\section{Wider considerations: the puzzle of egalitarianism}

Before we move to the empirical part it may be useful to recall that the issue of universality versus targeting makes up only one element in a wider 'puzzle of egalitarianism' (Alvarez 2001). After all, at the country level we are confronted with several empirical relationships that beg for a more thorough understanding. Lindert (2004) evokes the 'Robin Hood Paradox' "in which redistribution from poor to rich is least present when and where it seems most needed".

The connection between universality, the level of social expenditure and redistributive impact is part of a wider puzzle and it is important to be aware of this. For one, we know there also to be a strong relationship at the country level between wage (or market income) inequality and social expenditure. In other words, it is countries with egalitarian wage structures that tend to have universal welfare systems, generous benefits and, as a consequence, high social expenditures. This connection is again contra-intuitive, because at first sight, one would expect the opposite relation, namely that a greater wage disparity would require more redistribution, and, therefore, higher social expenditures. Hence, the causal chain may well start with institutions and policies shaping income distributions before taxes and transfers. For example, as argued by Bradley et al. (2003), the causal relationship between market inequality and redistribution occurs indirectly and is mainly due to the strong influences of labour unions and left parties. But it may also run in other ways.

Let us briefly discuss these alternative causal narratives. First, the direction of causality may go from an extensive welfare state to a condensed waged distribution. This is the line followed by Beramendi Alvarez (2001), who has argued that second-order effects of social expenditure are a large part of the explanation of the 'puzzle of egalitarianism'. First order effects of redistribution on inequality consist of direct income transfers from high-income to low-income households, through taxes, social security or social assistance. But second order effects are equally important: the higher taxes and transfers of large welfare states influence labour supply in such a way that a more condensed wage distribution results. High-wage 
earners substitute monetary income for leisure in response to taxes, while generous benefits reduce labour supply among those commanding low wages (through higher reservation wages). These second order effects may be highly contingent upon national institutions, particularly with regard to funding of the welfare state, the level of wage bargaining and fine details of institutional design.

Second, the causal mechanism between redistribution and inequality may run in the opposite direction. A highly unequal distribution of market incomes may make it politically and technically more difficult to redistribute income. McCarty and Pontusson (2009) review a number of political economy theories with regard to voter behaviour under different conditions of economic inequality. The so-called median voter models assume that changes in the income distribution lead to a shift in the preference of the median voter, or the 'political middle'. Moene and Wallerstein (2001, 2003) argue that under conditions of rising income inequality, the median voter has a preference for reduced expenditure on insurance and social spending. Earlier Meltzer and Richard (1981) formulated an opposing hypothesis, predicting that rising income inequality leads to a shift in preferences of the median voter towards more redistribution.

The evidence is quite mixed. Kenworthy and Pontusson (2005) find empirical support for the Meltzer and Richard thesis. "In contrast to widespread rhetoric about the decline of the welfare state, redistribution tended to increase in response to the rise in household market inequality. And it did so in proportion to the degree of increase in inequality, producing a strong positive association between changes in market inequality and changes in redistribution.” Milanovic (2000) finds a consistent association between gross household income inequality and more tax/transfer redistribution in a set of 24 democracies in the period of the mid seventies-mid nineties. More recently Olivera (2012), performing an analysis on a pool of 33 European countries, finds that inequality increases the demand for redistribution and that increases in income inequality stimulate the demand for redistribution. Yet the empirical evidence varies and some studies arrive at opposite conclusions (Iversen and Soskice: 2006, 2009; Finseraas 2009; McCarty and Pontusson 2009; Lupu and Pontusson 2011; Toth, Horn and Medgyesi, 2013).

As McCarty and Pontusson (2009) note, one clear complication is that the majoritarian assumption underlying the median voter models is not universally applicable. In many contexts, a vast number of parties (including trade unions, employers' organisations) compete for political influence. The partisan politics theory assumes that, rather than moving all parties either to the left or the right, income inequality can cause polarization of the electorate. As the political spectrum widens, the outcome depends largely on the extent to which low-income groups are mobilized, in terms of election turnout and union density. In turn, social security arrangements can strengthen trade unions, particularly in so-called Ghent countries where they are involved in the provision of unemployment benefits (Van Rie et al., 2011) Furthermore, the recent attention in the literature to insider-outsider conflicts and divergent interests within 'Labour' or 'the Left' are of key importance.

Third, causality between equality and redistribution may run in both directions, in a process of mutual reinforcement. This argument has been developed by Barth and Moene (2009) in a recent NBER paper. They argue that a more equal wage distribution leads to welfare generosity through a process of political competition. In turn, more income redistribution produces more equality. The authors hypothesize that this multiplier operates mainly through the bottom of the income distribution: the amplification occurs where wages at the bottom of 
the distribution are compressed, not where higher incomes are compressed. The hypothesis finds empirical support in their analyses on 18 OECD countries over the years 1976 to 2002.

Finally, an extensive welfare state, as well as a limited degree of wage inequality may both be the result of variables that determine both. As Atkinson (2000) suggests, countries may be characterised by notions of equity that are widely shared within any society, but that differ across societies. A society in which the value of solidarity is widely shared may simultaneously support pay norms, collective agreements and adequate minimum wages, as well as quasi-universal and generous benefits.

Thus, variables like wage dispersion, primary income inequality, generosity, universality, level of expenditures and disposable income inequality make up a complex web of interrelations of which the causalities can run in different directions. In this paper, the primary focus lies on the relationship between the factors of universality, generosity and income inequality.

\section{Measuring targeting and redistribution}

\subsection{Concepts and operational definitions}

Targeting, redistribution and generosity are key concepts in this paper. The aim of this section is to address the conceptual clarity of these terms, as misunderstandings related to their interpretations may easily arise (e.g. van Oorschot, 2002, p. 173). For instance, targeting is often equated with means-testing although it does not necessarily imply a means test, as other eligibility criteria (e.g. family composition) can be established to channel benefits to specific groups (e.g. lone parents). By contrast, 'universal' benefits are aimed at broad segments of the (national) population. Still, it should be noted that universal benefits are rarely truly universal, as they often apply for instance a residency criterion, which can be more or less strict. Moreover, whether benefits are flat-rate or earnings-related, is a question that is closely linked but distinct from universality or targeting.

Korpi and Palme employ three aspects to classify transfer systems: a) the basis of entitlement; b) the benefit level principle and c) the form of governance, particularly the extent of employer-employee corporation. In their classification targeted models have two distinguishing features: the basis of entitlement is proven need and benefits are there to provide a minimum income.

However, the actual operationalization they use in their 1998 article is much more straightforward and simple. It is also for that reason contestable on a number of grounds. In their 1998 ASR article they do not build on institutional indicators to gauge the level of targeting within tax/transfer systems. The extent of targeting is measured on the basis of a single outcome indicator, the targeting coefficient, which reflects effective redistributive outcomes rather than redistributive intentions, as we will argue below. This means that 'targeting' here is interpreted as social transfers being more beneficial for lower incomes, irrespective whether this comes about because of system characteristics like means testing ("income selectivity") or providing benefits for specific categories ("categorical selectivity"). Basically, this means that we look at the position of the beneficiaries in relation to the median (voter). 
In our analysis, targeting is measured in two ways: on the one hand we use the concentration coefficient of transfers in the same way as Korpi and Palme (1998) do. On the other hand, we also express it as a share of transfers going to the bottom quintile.

The concentration coefficient of an income component is calculated in a similar way as the Gini coefficient (see e.g. Kakwani, 1977; Lambert, 2002; OECD, 2008). The value of the concentration coefficient is derived on the one hand from the relative size of the transfer going to each income unit, and on the other hand from the ranking of each income unit, which determines its relative weight in the contribution to the concentration coefficient. The difference between the concentration and Gini coefficients lies in the variable according to which income units are ranked. With a concentration coefficient of an income component, income units are ranked according to income (and not by the income component itself), while for a Gini coefficient the focal variable and the ranking income variable are the same (namely income).

Concentration coefficients can also be considered as a summary indicator of the information provided by quintile distributions. When the concentration coefficient has a value that is lower than the Gini coefficient of the income on which its ranking is based, then lower incomes benefit relatively more: individuals receive a higher share of the income component than their share of income. Thus, these concentration coefficients provide insight into the propoorness of the various income components independent of their size. A concentration coefficient will be zero if all income units receive the same absolute amount of transfers ${ }^{1}$, which corresponds to the $45^{\circ}$ line in the Lorenz diagram. Hence, we can make a distinction here between weak and strong pro-poorness. Strong pro-poorness corresponds to a negative concentration coefficient (area A in Figure 1 below), whereas weak pro-poorness is captured by a concentration coefficient between zero and the value of the Gini coefficient of income (area $\mathrm{B}$ in Figure 1). When the value of the concentration coefficient is larger than the Gini, then the benefit is pro-rich (area $\mathrm{C}$ in Figure 1).

Figure 1. Pro-poorness and concentration coefficient

1 Though of course this does not mean that all concentration coefficients of zero correspond to equal absolute amounts over the income distribution. 


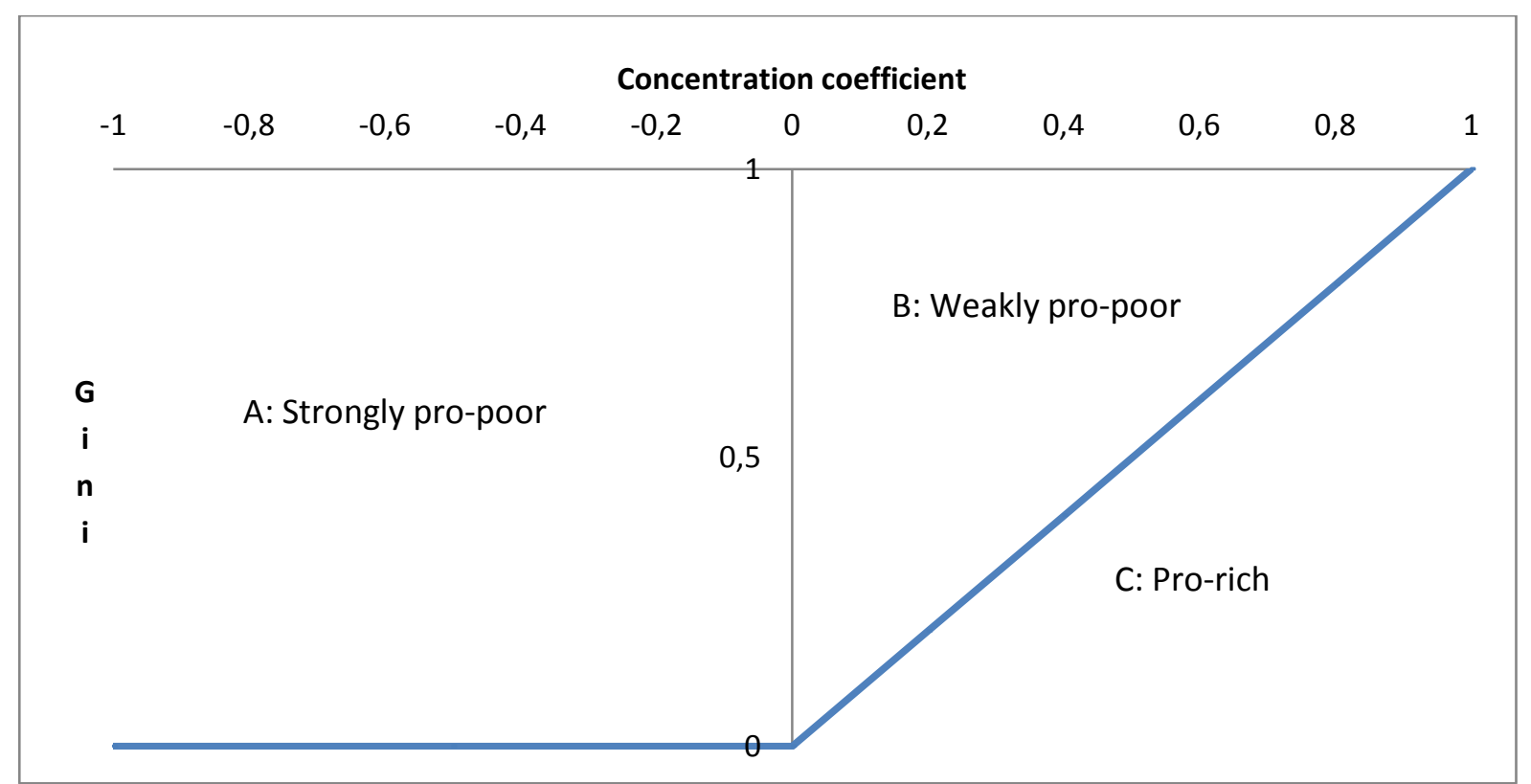

Source: own presentation.

As social transfers are composed of various transfer types (i.e. old-age pensions, family benefits, etc.), we try to identify the distributional properties and contribution of these income sources to the overall concentration coefficient. Following Kakwani (1977), we apply a factor decomposition analysis of the concentration coefficient: the concentration coefficient of total transfers $\left(C_{T}\right)$ can be decomposed as the sum of the concentration coefficients $\left(C_{i}\right)$ of the different transfer categories $i$ weighted by their share $s_{i}$ in total transfers $s$ :

$$
C_{T}=\sum_{i=1}^{n} \frac{s_{i}}{s} C_{T_{i}}
$$

Quintile distributions are based on five equal-sized population groups which are divided according to their income. Income units are ranked from low to high income. A comparison of the share of social transfers going to the bottom quintile with the corresponding concentration coefficient indicates how the concentration coefficient comes about: is it driven by targeting towards the bottom quintile (the poor), or are rather by patterns higher up the income ladder?

Note that we use the term 'targeting', which suggests that outcomes are due to the characteristics of the system, but this need not be the case. Moreover, the outcomes of a system are highly dependent on the characteristics of the underlying population, in terms of socio-demographic characteristics, income inequality, composition of income, etc. If, for instance, a benefit is designed in such a way that all children are eligible, but all children are situated in the bottom quintile, then this policy measure may appear as very targeted in its outcomes, even though its design may not include any means-testing or needs-based characteristic. This means that strictly speaking we cannot derive from the concentration coefficient or from the quintile distribution how pro-poorness of a transfer comes about.

In brief, the following factors may play a role:

- The design of the policy (eligibility; income or categorical selectivity; conditions for calculating the size of the transfer);

- Distribution of socio-demographic or other characteristics that determine eligibility and size of the transfer, and hence determine where transfers will be located in the income distribution; 
- The ranking of beneficiaries in the income distribution. This means that the same distribution of transfers will only result in different concentration coefficients if recipients have a different ranking in the underlying income distribution (e.g. market versus disposable income, see further).

The concept of redistribution refers to the impact of taxes and transfers on income inequality. The impact on inequality is driven by the size of transfers and taxes, as well as by their propoorness, i.e. whether these transfers are going relatively more to lower or higher incomes. Redistribution is measured by the difference between the Gini coefficients with and without tax-transfers relative to pre-transfer income; this corresponds in our analysis to the difference of the Gini coefficients of market and disposable income relative to that of market income.

Alternative measures of redistribution can also be used. For example, Kenworthy and Pontusson (2005) rely on the absolute difference between disposable and market income Gini coefficients, as it allows capturing redistribution that is not affected by (e.g. time variant) level changes of market income inequality. The redistributive effect of taxes, resp. transfer alone can be the focus too and is measured as the difference of the Gini coefficients of gross and disposable income relative to that of gross income, resp. the difference of the Gini coefficients of market and gross income relative to that of market income. In addition, Jesuit and Mahler (2010) suggest a measure of redistribution that captures the second-order effects of public pensions. This measure addresses the issue of artificially highly unequal market incomes, as elderly households relying on public pensions appear to be poor, though in the counterfactual scenario of no state pension provision they would have relied on other sources of income. Finally, the redistribution measures can be based on other than Gini indicators of income inequality, e.g. percentile ratios as in Mahler (2008). We test the impact of some of these alternative redistribution measures.

For indicating the impact of the size of transfers, we use the concept of generosity: how much is spent on social transfers? Generosity is measured here by expressing average social transfers as a share of average income (either market income, gross income or disposable income). An alternative measure is also used for the sensitivity analysis: cash social spending as percentage of GDP (for a further discussion on the pros and cons related to diverse measures of welfare state generosity see e.g. Allan and Scruggs, 2004).

\subsection{Choice of income}

Overall, the building blocks of our analysis consist of some commonly used income concepts, namely market income, social transfers, gross income and disposable income ${ }^{2}$. These income concepts are constructed in such a way that they cover exactly the same components as in Korpi and Palme, unless specified otherwise ${ }^{3}$.

Note that in the distributional analyses negative incomes are set to zero.

As we show in Appendix 1, seemingly the same income concepts, if taken from different data sources, could have a different composition regarding individual components. 
In brief, market income includes income from labour and capital, as well as mandatory individual and occupational pensions (or further referred to as "occupational pensions") 4 . Gross income is defined as market income plus social transfers plus net transfers between households. Social transfers consist of the total of work-related insurance transfers, universal benefits and social assistance benefits ${ }^{5}$. Finally, disposable income is arrived at when deducting taxes from gross income. These taxes refer to personal income taxes and social contributions (excluding employer contributions).

For the distributional analyses, all relevant revenues are pooled at the household level and the individual is the unit of observation. An equivalence scale is used to correct for household size. We apply the same equivalence scale as in Korpi and Palme (1998), namely the square root of household size.

We use different income concepts to rank equivalised incomes when calculating quintile distributions and concentration coefficients. In a first instance we use the same income concept to rank income units as the one used by Korpi and Palme (1998), as well as by Kenworthy (2011), namely gross income, or 'Who gets what after social transfers but before taxes'. Of course, there are arguments to use other income concepts for ranking individuals. The most obvious candidates are market income and disposable income, which are also the income concepts used to calculate the redistributive effect in Korpi and Palme (1998) and in this paper. With market income (or 'Who gets what before taxes and transfers'), income units are ranked according to the position they take in the hypothetical situation that there would be no social redistribution. This effectively puts households that rely solely on transfers at the bottom of the distribution. By definition the impact of the transfer is very large. This makes more sense for people who fail to gain access to the labour market whereas they are supposed to be economically self-reliant. They would probably have no other means of existence. But this is a stronger assumption for the elderly who rely on public pensions. In the counterfactual scenario they would probably have saved. Thus in calculations based on pre transfer rankings, retired households count as extremely poor and they populate the very bottom of the distribution. This probably overstates the impact of social transfers on the income distribution. For this reason Whiteford (2010) and OECD (2008) use disposable income (i.e. 'Who gets what after taxes and transfers') as the ranking measure. The drawback here is that the impact of the welfare state may be underestimated. Some pensioners, for example, might have occupied an entirely different position in the income distribution in the absence of a public pension system. In our empirical application, we test the sensitivity of the results for using either market or disposable income as ranking measure.

If taxes and transfers do not alter the ranking of income units, then concentration coefficients will be the same for all three income concepts. In practice, income units do change ranks. Especially the inclusion of social transfers (i.e. moving from market to gross income) causes income units to change rank, implying that concentration coefficients can substantially differ

4 LIS has recently reclassified some income concepts, notably occupational pensions, which are now part of social (security) transfers. We explore the implications of this income classification (change) in the sensitivity part of our analysis, when we compare the "old” and the "new” LIS terminology.

5 Essentially, social transfers are equivalent to "social security redistribution" transfers based on the most recent LIS terminology, except of the above mentioned mandatory individual and occupational pensions. This implies, that the "old" LIS classification refers to higher market income, but lower social transfers in comparison to the new terminology. The concept of gross income is not affected by this methodological change. 
when market income compared to gross or disposable income is used. Reranking due to taxes (i.e. moving from gross to disposable income) is in general much smaller, implying that concentration coefficients based on the ranking of either gross or disposable income will probably not be very different.

\subsection{Main and sensitivity analysis}

As this article seeks to replicate the findings by Korpi and Palme and subsequent studies, we aim for maximum comparability of concepts in the main analytical part. Here, we reproduce the "original" relationship between targeting and redistribution as displayed in Korpi and Palme (1998) and later on in Kenworthy's (2011) study. Our selection of the countries covers the "original" set, but also goes beyond it, as the LIS database has expanded its country coverage substantially. Furthermore, for a better understanding of the driving forces of the targeting and redistribution relation, we decompose the concentration coefficient over separate transfer types, and we analyse how targeting and redistribution relate to the generosity of social transfers.

We challenge most of the "original” methodological choices in the sensitivity analysis part: country selection, data source, choice of the ranking income type and classification of social transfers. A number of other sensitivity checks have also been made, but are not reported in the main text of this study. For example, the impact of using alternative measures (as on targeting) is noted in the footnotes with the corresponding graphs in Appendix 2. A few other sensitivity tests, such as checking the influence of using a different equivalence scale, are not reported due to their smaller influence on the main findings in comparison to the aforementioned methodological choices.

\subsection{Data}

In the main analytical part, indicators are calculated on the basis of the micro survey data of the Luxembourg Income Study (LIS), in line with the approach of Korpi and Palme (1998) and Kenworthy (2011). We include the following countries, referring to 2004 (unless specified otherwise between brackets after the country's name): Australia (2003), Austria, Belgium (2000) Canada, the Czech Republic, Denmark, Estonia, Finland, France (2005), Germany, Greece, Hungary (2005), Ireland, Israel (2005), Italy, Luxembourg, the Netherlands, Norway, Poland, Slovenia, Spain, Sweden (2005), Switzerland, United Kingdom, United States. LIS tries to provide datasets that are as comparable as possible ${ }^{6}$. However, some issues remain.

For example, one of the major issues relevant for our study is the fact that not all LIS national datasets include gross income amounts, implying that gross income in fact corresponds to disposable income and that market income does not include taxes. This is the case for Belgium, Greece, Hungary, Slovenia and Spain. Taxes are also only partially captured in the French and Italian data. This implies that (part of) social transfers are net of taxes in these

6 More details on methodological aspects concerning LIS data can be found in Appendix 1. 
countries, whereas in the other countries gross transfers (i.e. before deduction of taxes) are used. This is particularly relevant for countries where transfers are subject to substantial taxation, as is the case in the Nordic countries. It also means that the value (and distribution) of available gross income is lower (different) for the countries having not full tax information in the dataset. We tackle this "net/gross" issue in the sensitivity part of our analysis.

In the sensitivity analys, we also compare the main outcomes calculated on LIS data with the outcomes computed on EU-SILC 2005 data, which covers 25 EU countries at the time, plus Iceland and Norway (incomes refer to 2004). For a number of European countries (i.e. Austria, Estonia, Greece, Spain, Ireland, etc.) the LIS dataset is actually derived from the national EU-SILC surveys - seemingly, the most common type of LIS information source for the European countries as of mid 2000's.

When using EU-SILC data, we apply income definitions that are as close as possible to the ones used by Korpi and Palme with the LIS dataset. Such alignment is needed as original (EUROSTAT) income definitions of, for example, gross income are somewhat different from those used in the LIS dataset. A more detailed explanation of differences and similarities between the LIS and EU-SILC data is provided in Appendix 1.

\section{Results}

\subsection{Main analysis}

\subsubsection{Targeting and redistribution: the starting point}

As our first aim is to replicate the earlier findings (see Appendix 2) for more recent data, we start our analysis by using the same concepts, operationalisations and data (LIS) as Korpi and Palme (1998) and Kenworthy (2011). We relate the concentration coefficient of social transfers (with income units ranked according to gross income) to the redistributive effect of taxes and transfers, as measured by the difference between the pre and post-tax/transfer Gini coefficient (see Figure 2). We extend the country coverage in comparison to the previous studies.

Let us first consider the two key variables in Figure 2 separately, starting with our measure of targeting ${ }^{7}$. All concentration coefficients are smaller than the Gini coefficient of gross income, which means that all systems are progressive (i.e. pro-poor). There is however wide variation in the spectrum of targeting-universality. Remember, that the smaller/more negative the concentration coefficient is, the more targeted the transfers are whereas the closer the concentration coefficient is to the Gini, the more universal transfers are. Australia, the United Kingdom and, maybe somewhat surprisingly, Denmark have the most negative concentration coefficients and can be characterized as strongly pro-poor. Negative concentration coefficients are found in the majority of the countries, pointing to a substantial degree of targeting. In nine countries though, such as e.g. Southern Europe, Austria, France, Poland or

Note that, as shown in appendix Figure A.5 of Appendix 2, concentration coefficients match quite closely to an alternative measure of targeting: the share of transfers going to the bottom quintile. 
Hungary, we find positive concentration coefficients, and thus weak pro-poorness of transfer systems.

Figure 2. Concentration index (ranking by gross income) and redistributive impact, mid 2000s

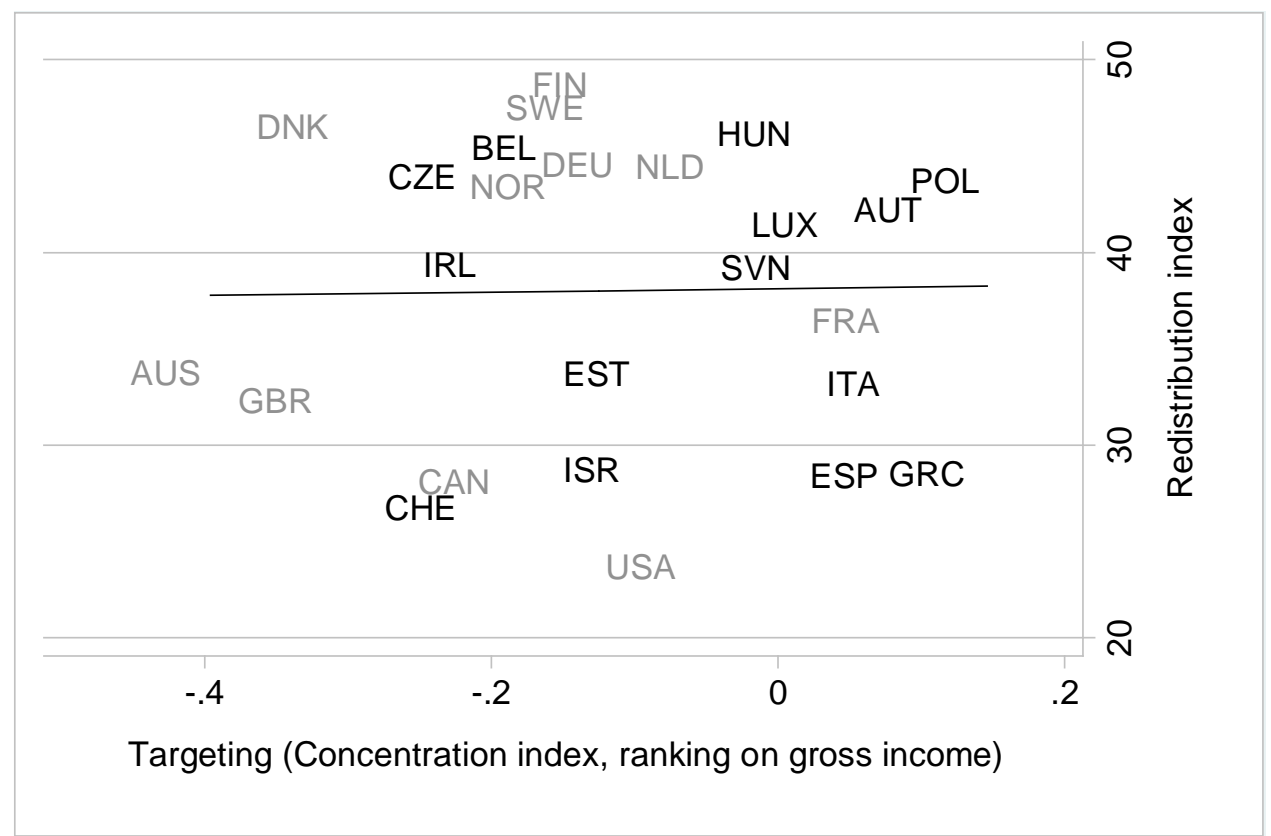

Note: 1) Due to data availability disposable instead of gross incomes are used for Belgium, Greece, Hungary, Slovenia and Spain; part of "gross" incomes are reported net of taxes for Italy and France. 2) The countries included in Korpi and Palme (1998) are in grey font.

Source: own calculations using LIS data

Turning to our measure of redistribution we also observe a considerable cross-country variation. The Nordic countries, such as Finland or Sweden, but also Belgium, Germany, the Netherlands, Hungary or the Czech Republic take positions as leading redistributing countries. The Southern European countries, the United States, Canada, Switzerland and Israel are at the other side of the spectrum.

Let us now consider the relationship between the degree of targeting and redistributive impact - from the perspective of the $\mathrm{x}$ and $\mathrm{y}$ axes.

Especially noteworthy at the very left hand side of the $\mathrm{x}$ axis are Australia, the United Kingdom and Denmark: they are all characterized by the strongest pro-poor benefit systems of all countries ${ }^{8}$. Yet the redistributive impact in Denmark appears much stronger. Similarly, looking at the countries with still strong pro-poor spending (concentration indices between about -0.3 and 0 ), the corresponding redistributive impact differs a great deal. Some of the countries with the strongest redistributive tax/transfer systems are to be found here (Sweden and Finland), together with some countries with the weakest redistribution (the USA, Canada, Israel and Switzerland). In summary, no clear relationship is found between targeting and redistribution among the countries with a negative concentration coefficient. A more clear and

8 Here and further on, the discussed country groups or specific value ranges of the concentration/redistribution indices are estimated using a cluster analysis. 
negative relationship, however, appears when focusing on the right hand side of the graph. This concerns the countries with positive targeting coefficients and thus countries with weak pro-poor spending: France, Italy, Spain, Austria, Poland and Greece.

Looking at this graph from the perspective of the y axis (the extent of redistribution achieved by the tax/transfer system) essentially yields a similar picture of wide cross-country variation. We also observe an extremely scattered range of values for the targeting measure in the countries with moderately high levels of redistribution (from about 30 to 40 per cent reduction of the post-tax/transfer Gini as compared to the pre-tax/transfer level). It ranges from the strongest pro-poorness of almost -0.4 observed in Australia to weak pro-poorness in countries like Italy or France.

In summary, our major finding - against the background of the earlier discussed literature - is that actually there is no clear relationship between targeting and redistributive impact for more recent years. This may partly be due to the fact that more countries are included in our analysis. But also other factors may play, which will be put to the test in the sensitivity analysis part of this paper.

\subsubsection{A more refined redistribution coefficient}

Korpi and Palme (1998) have used a broad index of redistribution, as they look at the difference between the Gini coefficients of market and disposable income, i.e. the combined effect of taxes and transfers. However, for their measure of targeting, they only look at the way transfers are distributed. Hence, we think that it would actually be more coherent to measure redistribution as the difference between the Gini coefficients of market and gross income (i.e. capturing the effect of transfers only), as is presented in Figure 3. By doing this the initial relationship found by Korpi and Palme seems to re-emerge, though this association is still a very weak one. Hence, we assert that the main conclusion from Figure 2 still holds: the relationship between targeting and redistribution has become very weak. Throughout this paper, we will continue to use the redistribution indicator that Korpi and Palme have used, as they are our point of reference), and look at the sensitivity of outcomes of changing one parameter at the time. But in subsequent studies on this topic we recommend to apply coherence between the targeting and the redistribution concepts. Moreover, a comparison of Figures 2 and 3 also indicates that the role of taxes in the redistribution process merits further investigation, not only because the redistributive effect of taxes differs across countries, but also because transfers are taxed in very different ways, with typically high burdens in the Nordic countries and low or no taxes in other countries. 
Figure 3. Measuring redistribution as the effect of transfers only

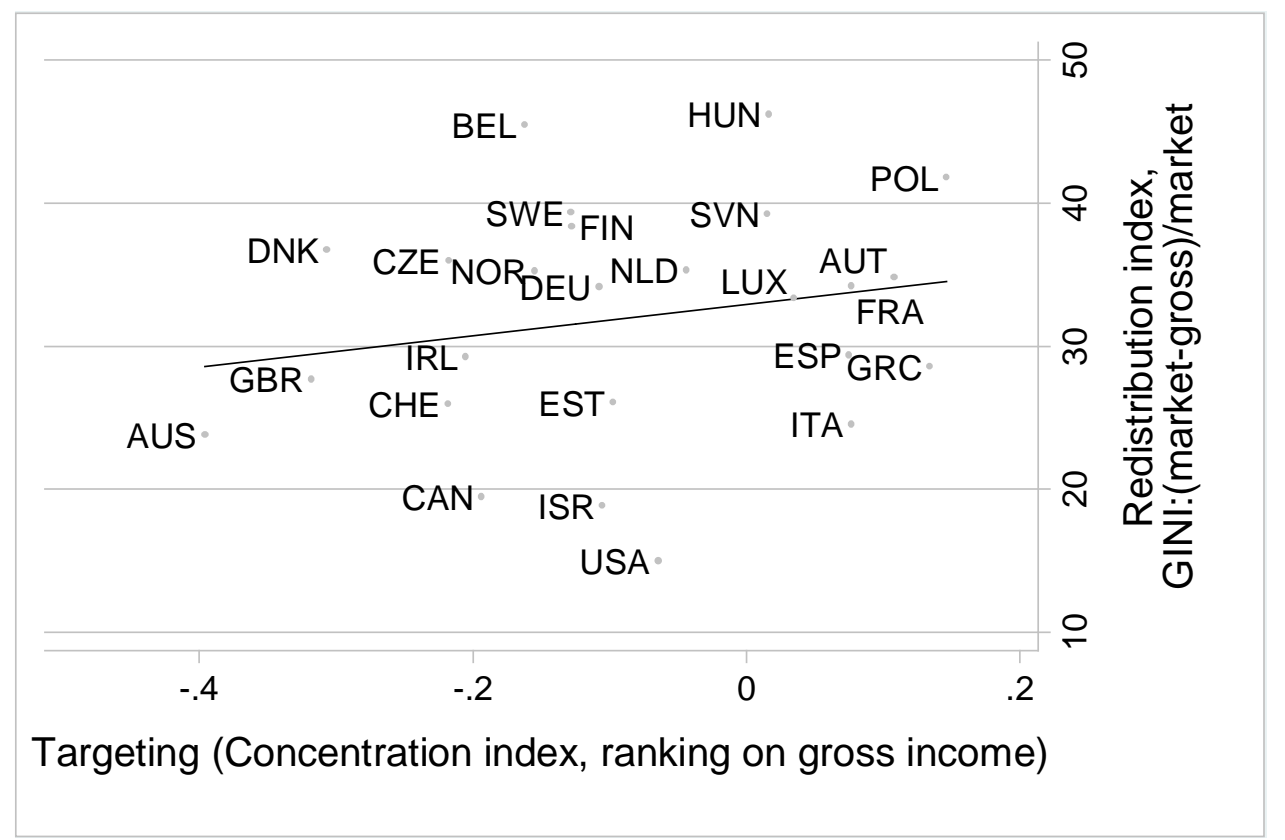

Notes: due to data availability disposable instead of gross incomes are used for Belgium, Greece, Hungary, Slovenia and Spain; part of "gross" incomes are reported net of taxes for Italy and France.

Source: own calculations using LIS data

\subsubsection{Decomposition of concentration coefficient}

As noted earlier, the high degree of targeting should not necessarily imply an extensive usage of means-tested benefits (i.e. minimum income protection schemes) but rather reflect the socio-demographic profile of beneficiaries. For example, a universal old-age pension system may be characterised as highly targeted if the elderly disproportionately cluster at the lower end of the income distribution. To better understand the main drivers of the concentration coefficients' values, we employ a factor decomposition analysis. Unfortunately, the decomposition cannot be done for all countries, as often LIS data information is missing to distinguish individual transfer categories.

First, we evaluate the individual input of social assistance benefits as opposed to other transfers. This already gives a flavour of how the design of systems operates, as these social assistance benefits are by default designed to target the most income vulnerable people. The social assistance income category pools diverse assistance benefits, such as general social assistance, but also assistance benefits in case of old-age, disability and various other circumstances (e.g. family, education).

Second, we evaluate the individual input of three major categories of social transfers by need function: old-age pensions, family benefits and a residual category of other active age benefits. Old-age benefits consist of the following LIS variables: old-age insurance public 
pensions, old-age universal pensions and old-age assistance pensions ${ }^{9}$. Family benefits cover maternity/parental wage replacement, family/child universal benefits and family/maternity/child assistance income variables. The other active age benefits refer to a range of diverse social security benefits, such as sickness wage replacement, disability or survivor pensions, unemployment or education benefits, etc.

Figure 4. Concentration indices of social assistance and other transfers

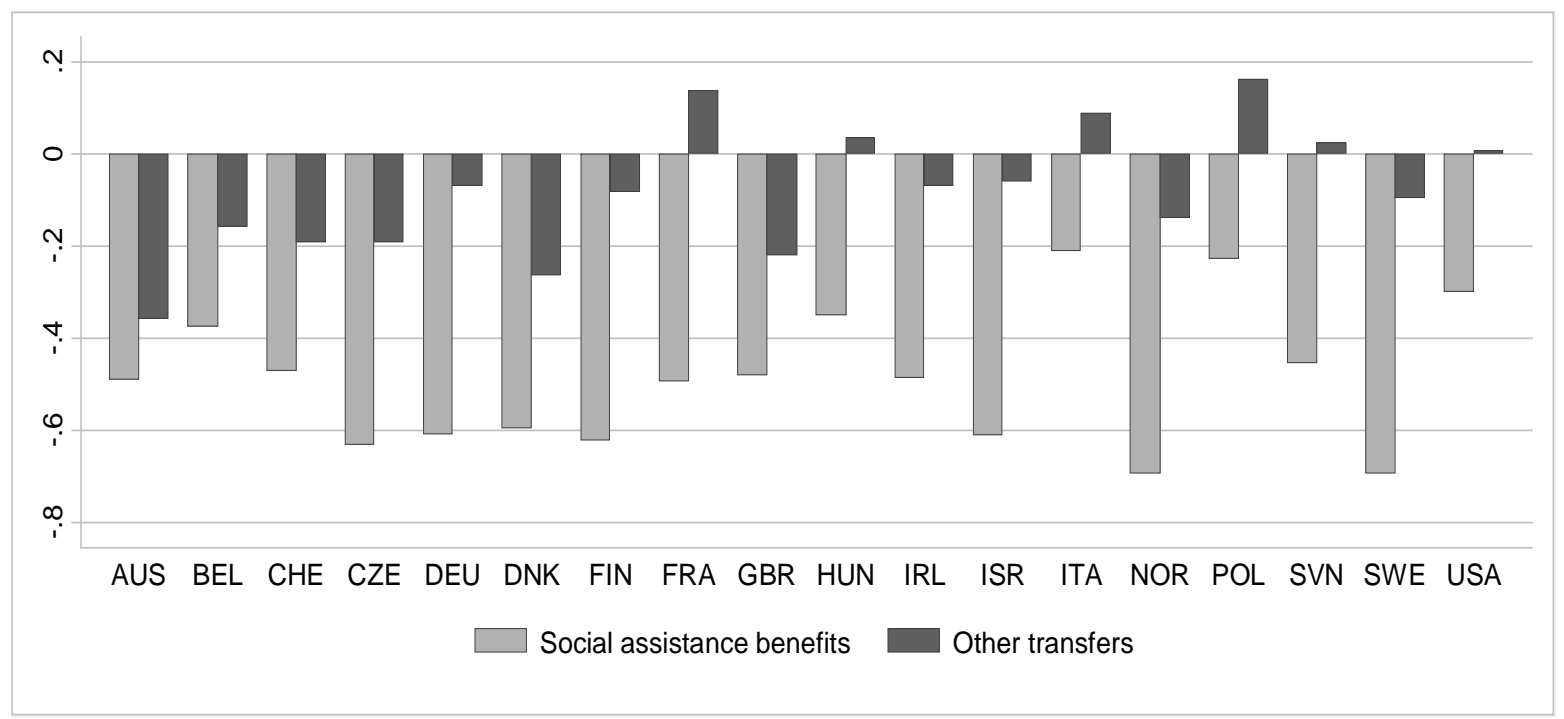

Notes: due to data availability disposable instead of gross incomes are used for Belgium, Greece, Hungary, Slovenia and Spain; part of "gross" incomes are reported net of taxes for Italy and France; Source: own calculations using LIS data

The targeting degree of social assistance benefits is, as expected, much higher than that of other social transfers: for all countries the concentration indices are lower (and always negative) than of those of other social transfers (see Figure 4). The variation of targeting is highly diverse, ranging from about -0.7 in Sweden to about -0.2 in Italy. This very strong targeting in comparison to other social transfers is an important driver of overall targeting, though much depends on the size of these transfers, as is shown in Figure 5. Even though social assistance benefits are relatively small in all countries (from about $2 \%$ in Belgium and Slovenia to about $38 \%$ in the UK), their contribution to the overall concentration index is not negligible. In Ireland, for instance, social assistance benefits make up around 33\% of total social transfers, but they contribute for almost $80 \%$ to the concentration coefficient of total transfers. Social assistance also contributes to more than half of the total concentration coefficient in the United Kingdom and Slovenia. Overall, this signals that despite the relatively small size (as for instance in the case of Slovenia), social assistance benefits play a significant role in determining the level of the overall concentration index, and thus the relationship between targeting and redistribution as portrayed in Figure 2.

Furthermore, we find a clear association between the targeting degree of social assistance benefits and redistribution: the higher targeting of these benefits, the more redistribution is achieved (Figure 6). Conversely, no association is found between targeting of other social transfers and redistribution. 
Figure 5. Social assistance: relative size and contribution to the concentration index

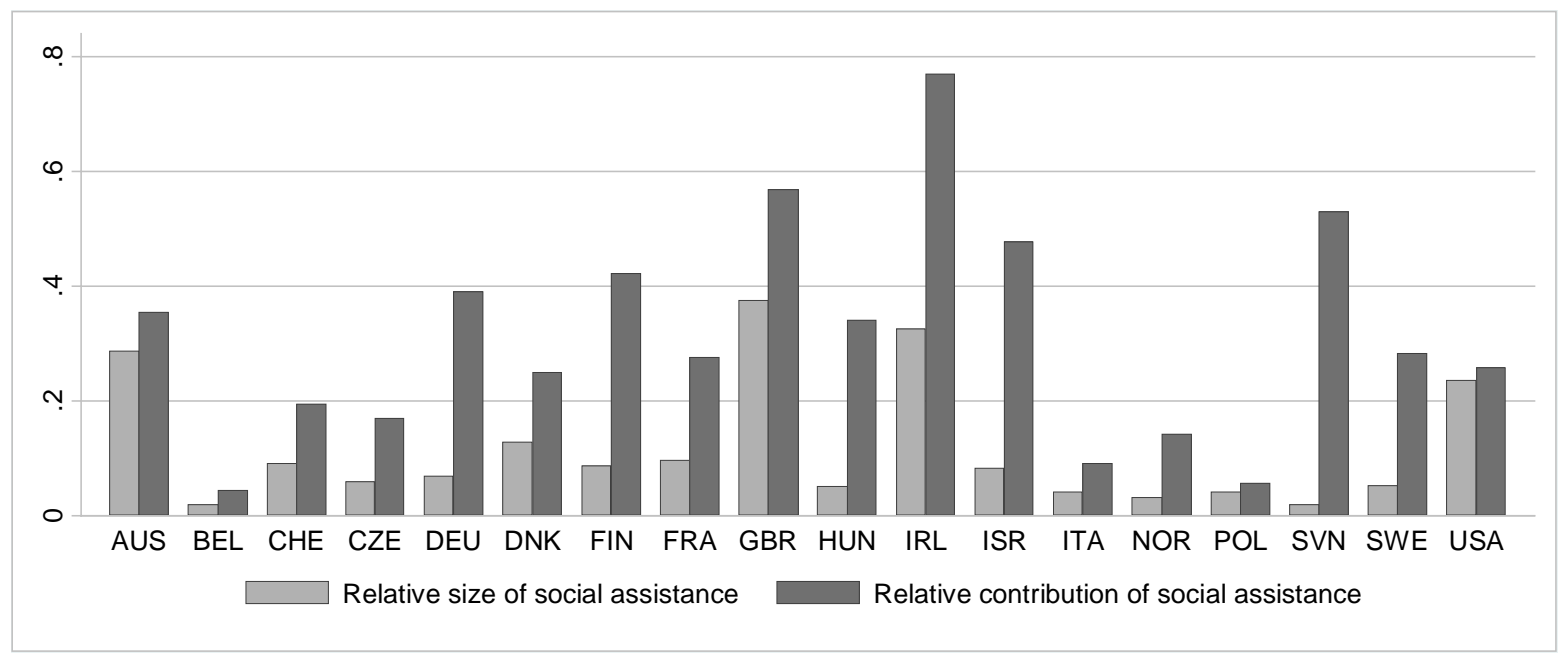

Notes: due to data availability disposable instead of gross incomes are used for Belgium, Greece, Hungary, Slovenia and Spain; part of "gross" incomes are reported net of taxes for Italy and France; the ratios of contribution are of minus sign in France, Hungary, Italy, Poland, Slovenia, and have been rescaled to represent the share of total concentration coefficient without the directional effect 10.

Source: own calculations using LIS data

Figure 6. Social assistance and the rest of social transfers: targeting and redistribution

Panel (A)

Redistribution due to social assistance benefits

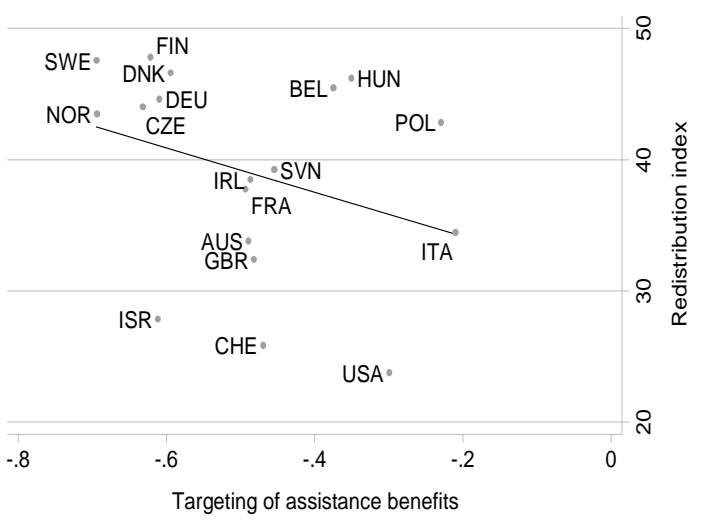

Panel (B)

Redistribution due to other transfers

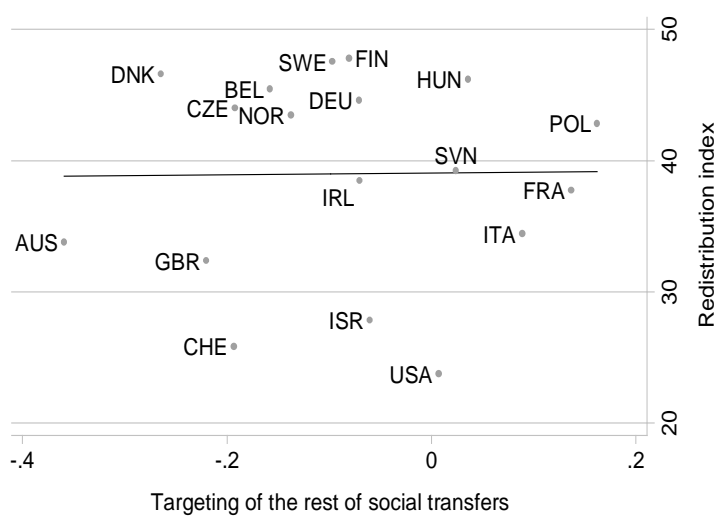

Notes: due to data availability disposable instead of gross incomes are used for Belgium, Greece, Hungary, Slovenia and Spain; part of "gross" incomes are reported net of taxes for Italy and France;

Source: own calculations using LIS data

10 As social assistance benefits and other transfers have concentration coefficients with opposite signs in these countries, the negative contribution of e.g. social assistance (i.e. -1.0639 in Hungary) is counteracted by the positive contribution of other transfers (i.e. 2.0639 in Hungary) so that the total sum still adds up to 1 . In rescaling to the share without the directional effect, the contribution of social assistance in e.g. Hungary is transformed to 0.34 relative contribution to the value of total concentration index. 
Figure 7. Concentration indices of social transfers - decomposition by type

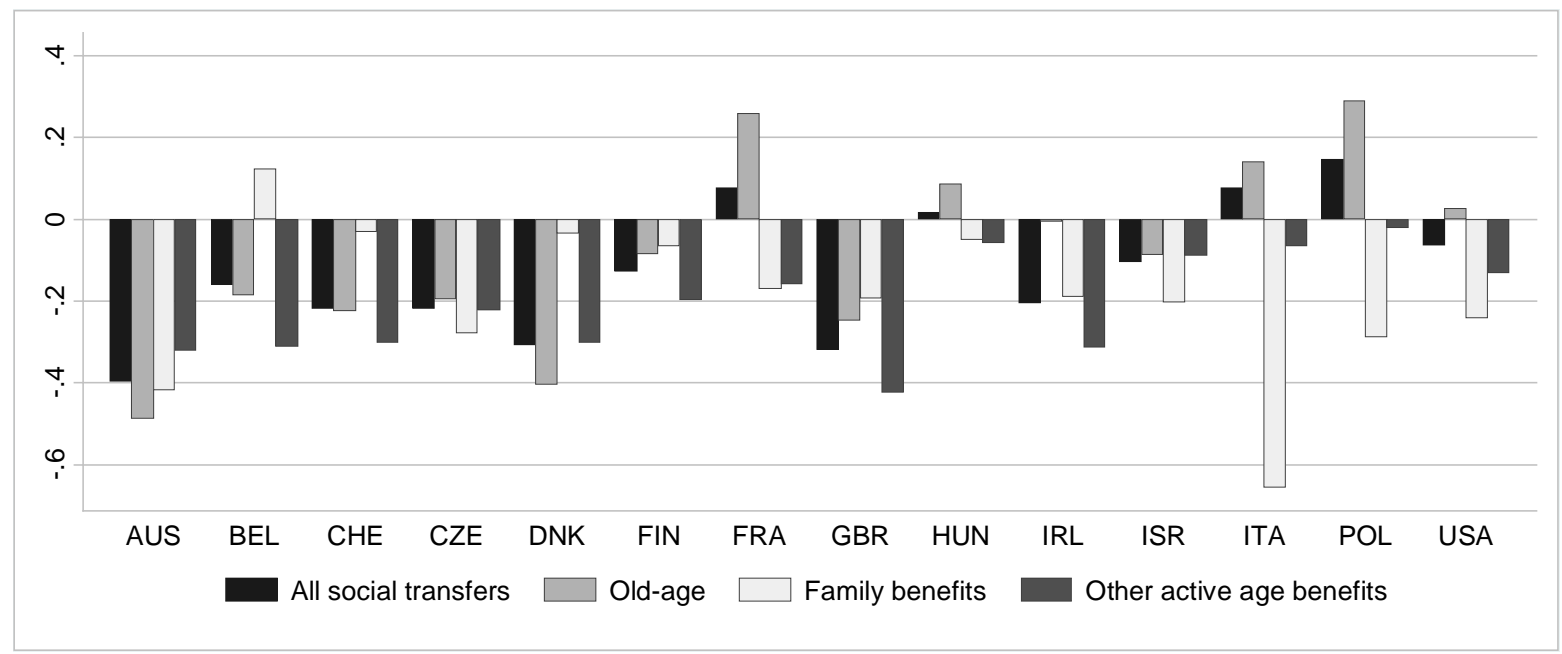

Source: own calculations using LIS data

A decomposition of social transfers by their need function is given in Figure 7 for those countries where we can distinguish between old-age, family and other active age transfers. The overall concentration index of social transfers is usually of the same sign as the concentration index of old-age pensions, no matter of how targeted the other two types of social transfers appear. The exception is the United States, where the concentration index of social transfers is slightly negative, but the concentration index of old-age pensions is positive, pointing to the stronger influence of the other active age transfer types. The degree of targeting of old-age pensions is highly varied. For example, in Australia, Belgium, Switzerland, and particularly Denmark, the old-age pensions are (much) more pro-poor in comparison to the other categories. In the Czech Republic, Finland, the Great Britain and Israel, at least one type of social transfers is more targeted at the poor than old-age pensions.

Finally, in the countries with positive targeting coefficients, namely France, Hungary, Italy and Poland, old-age pensions are driving the weak overall pro-poorness of social transfers, against the strong pro-poorness of family and other active age benefits. In other countries weak pro-poorness of the transfers is rare, with exceptions in the United States for old-age benefits and in Belgium for family benefits.

In Figure 8 we report the contribution of each transfer category to the total concentration index of social transfers. This confirms that old-age pensions are the primary source for the level and sign of the total concentration index in France, Hungary, Italy and Poland, all countries with positive concentration index values. In the other countries, family and other benefits together have a larger influence than old-age pensions, though with high variation. For example, all three social transfer types are of equal importance in Austria, whereas the contribution of the old-age pensions is by far the smallest one among the three types of social transfers in Ireland and the United States. 
Figure 8. Factor decomposition of CI of social transfers - contributions

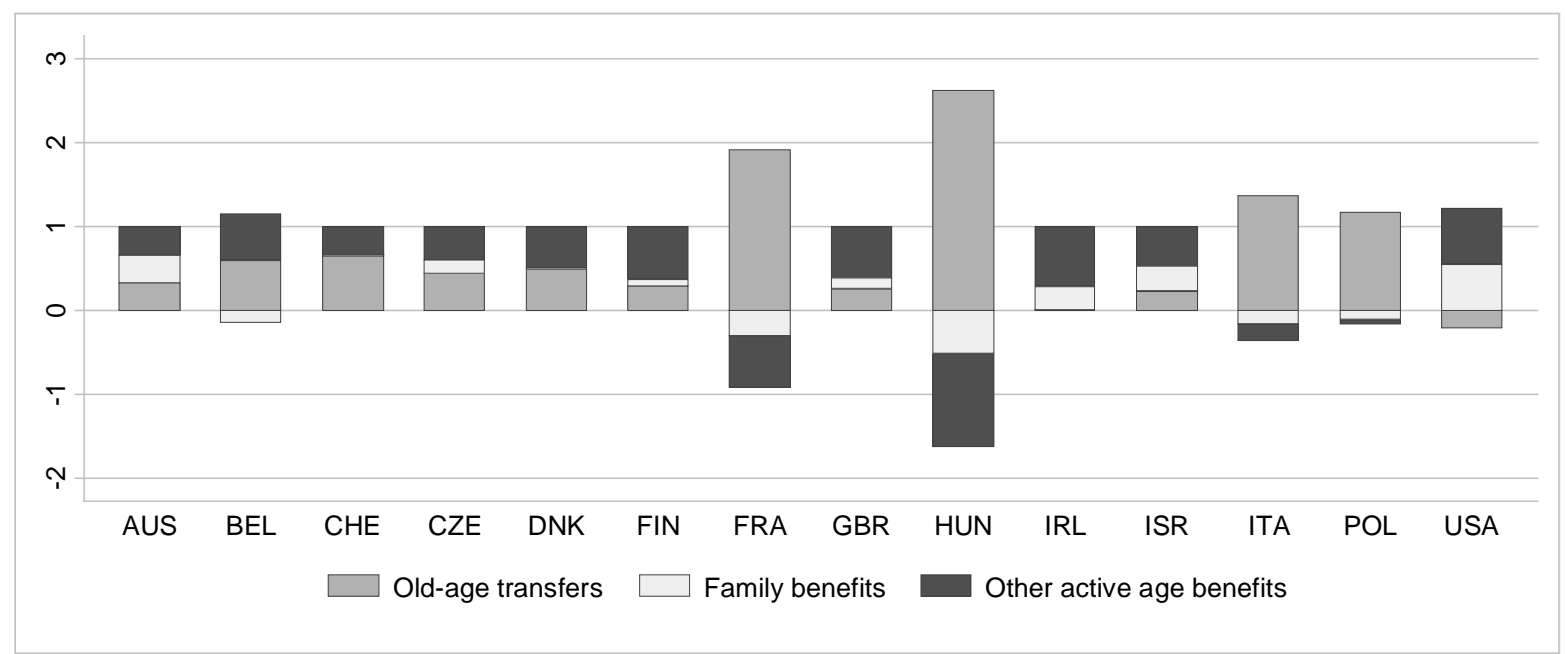

Source: own calculations using LIS data

Figure 8 also highlights that often the distributional properties of family benefits are rather different from old-age pensions, with Belgium being the prime example. Besides, family benefits also have the widest spectrum of the targeting degrees, as shown in Figure 7. But despite this wide range of targeting degrees of family benefits, we find a positive relationship between targeting of family benefits and redistribution (see Figure 9, Panel A). No such relationship could be traced for either old-age pensions or other active age benefits. This implies that the relationship (or rather absence of it) in our Figure 2 is actually driven by the distributional features of these two types of transfers (i.e. unemployment, disability, social assistance, etc.) rather than benefits aimed at families with children.

Figure 9. Concentration index of social transfers (ranking on gross incomes) and redistribution index

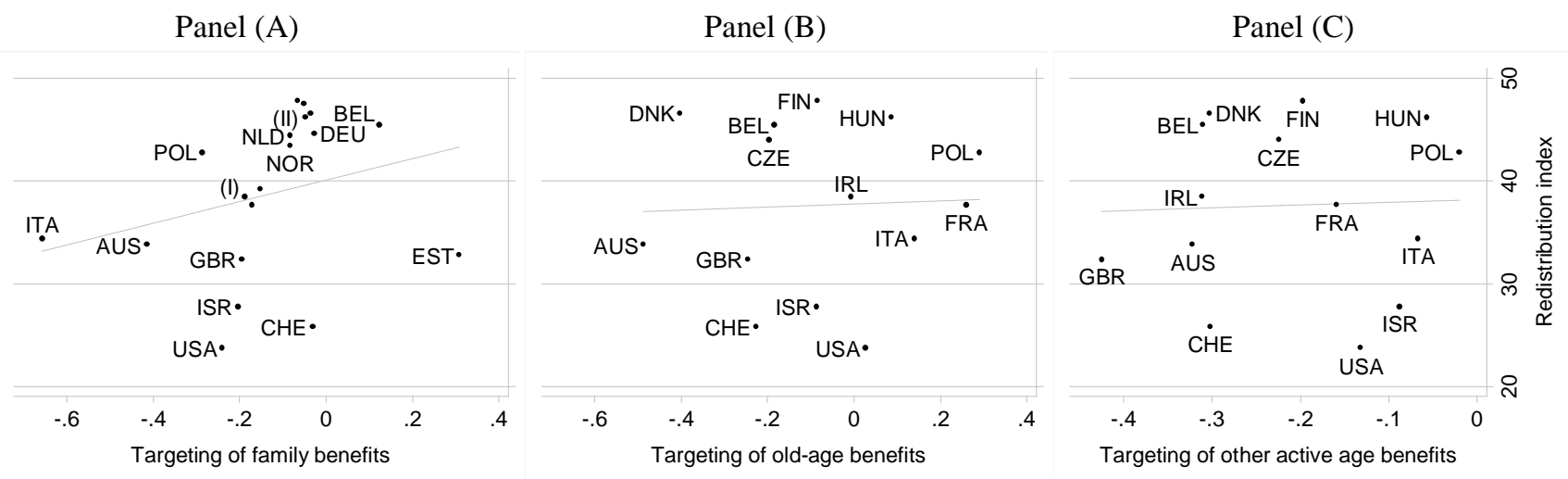

Note: (I) - refers to the group of countries: FRA, SLN, IRL; (II) - DNK, FIN, SWE, HUN.

Source: own calculations using LIS data

\subsubsection{A link to generosity}

Recall that there are two causal steps in Korpi and Palme's thesis. First, universal systems tend to be larger systems, spending more on the poor and non-poor alike. Second, larger systems tend to be more redistributive. 
Figure 10 shows the first part of this causal chain, setting the concentration coefficient against the measure of generosity we use here (share of transfers in gross income). The graph shows that weaker targeting is associated with higher generosity ${ }^{11}$. Although in line with Korpi and Palme, the relationship is a relatively weak one with again a lot of cross-country variation. A strongly pro-poor system like Denmark's, for example, is not smaller than weakly pro-poor systems like Spain, Italy or Greece.

Figure 11 shows the second step in the causal chain and links generosity to redistributive impact. Here the relationship is positive and it is also relatively consistent. There is not a single system achieving a strong redistributive impact with a low level of spending and, conversely, higher levels of spending tend to be associated with stronger redistributive impacts. This is consistent with the findings from a host of studies (Nolan and Marx, 2009; OECD, 2008 and 2011). Note here that the strongest redistributive impact is achieved by countries that combine moderate (Sweden and Finland) to strong targeting (Denmark) with comparatively high levels of spending. This marks the difference from a country like Hungary, which achieves very high redistribution with an extremely high level of spending but weak pro-poor targeting.

Figure 10. Concentration index (ranking by gross income) and generosity, mid 2000s

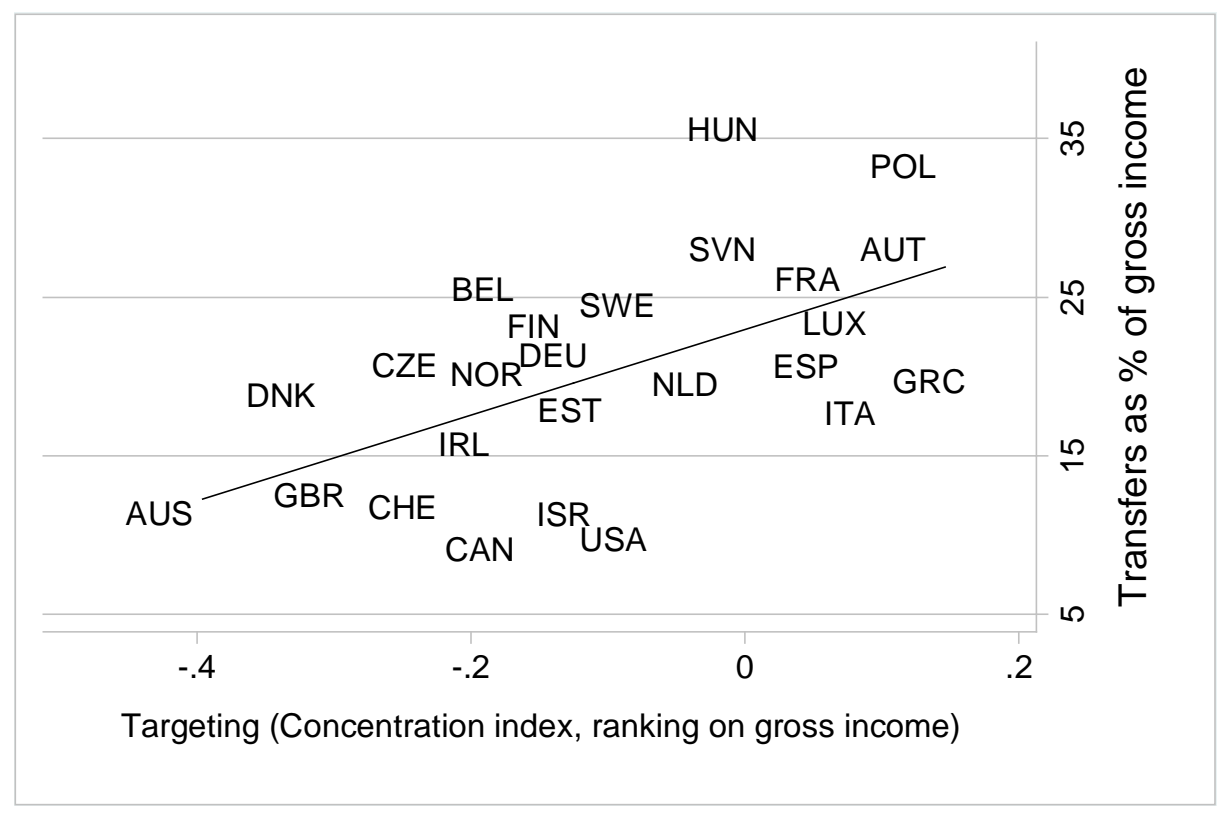

Note: due to data availability disposable instead of gross incomes are used for Belgium, Greece, Hungary, Slovenia and Spain; part of "gross" incomes are reported net of taxes for Italy and France.

Source: Luxembourg Income Study

11 Similar pattern emerges when cash social spending as a share of GDP is used as an alternative indicator for generosity, see Figure A.4 in Appendix 3. 
Figure 11. Reduction in inequality due to taxes and transfers compared with size of social transfers (expressed as a share of gross income), mid 2000s

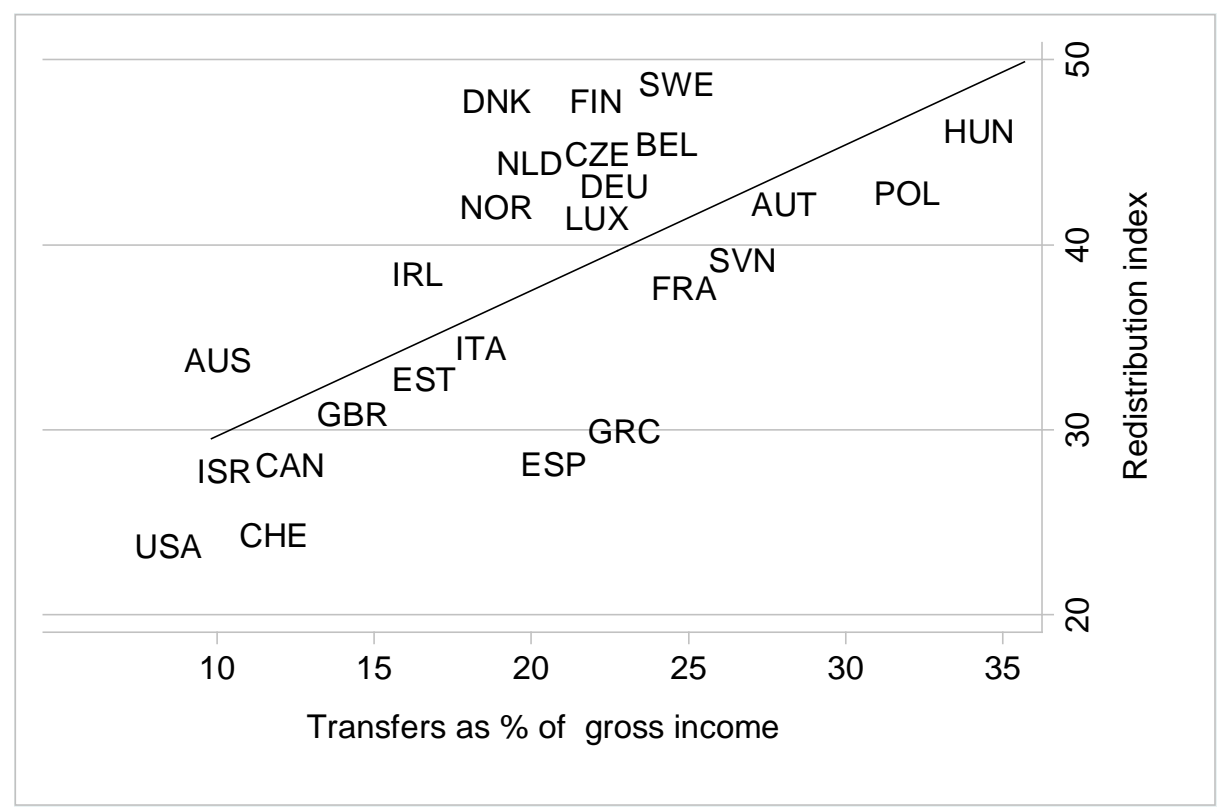

Note: due to data availability disposable instead of gross incomes are used for Belgium, Greece, Hungary, Slovenia and Spain; part of "gross" incomes are reported net of taxes for Italy and France.

Source: Luxembourg Income Study

\subsection{Sensitivity}

How robust are these results? They depend on a number of choices in our approach and changing one of the parameters may considerably affect the outcomes and hence conclusions. We test the sensitivity of the results for changes in a) the choice of the ranking income concept, b) the role of taxes, c) the role of mandatory individual and occupational pensions and d) the choice of the data source.

\subsubsection{The choice of the ranking income concept}

In this section, we look at the effect of changing the variable used to rank incomes when calculating the concentration coefficients. The ranking determines the weight of the income unit in its contribution to the concentration coefficient. Changing ranks thus affects the weights, and consequently the value of the concentration coefficient.

So far results have been calculated using gross income as the pivotal income concept (notably for ranking income units and determining generosity). When this is shifted towards disposable income (as is done in e.g. Whiteford, 2010 and OECD, 2008), roughly the same pattern as in our main analysis emerges (see Figure 12): no relationship between targeting and redistribution. 
Figure 12. Concentration index (ranking on disposable income) and redistributive impact

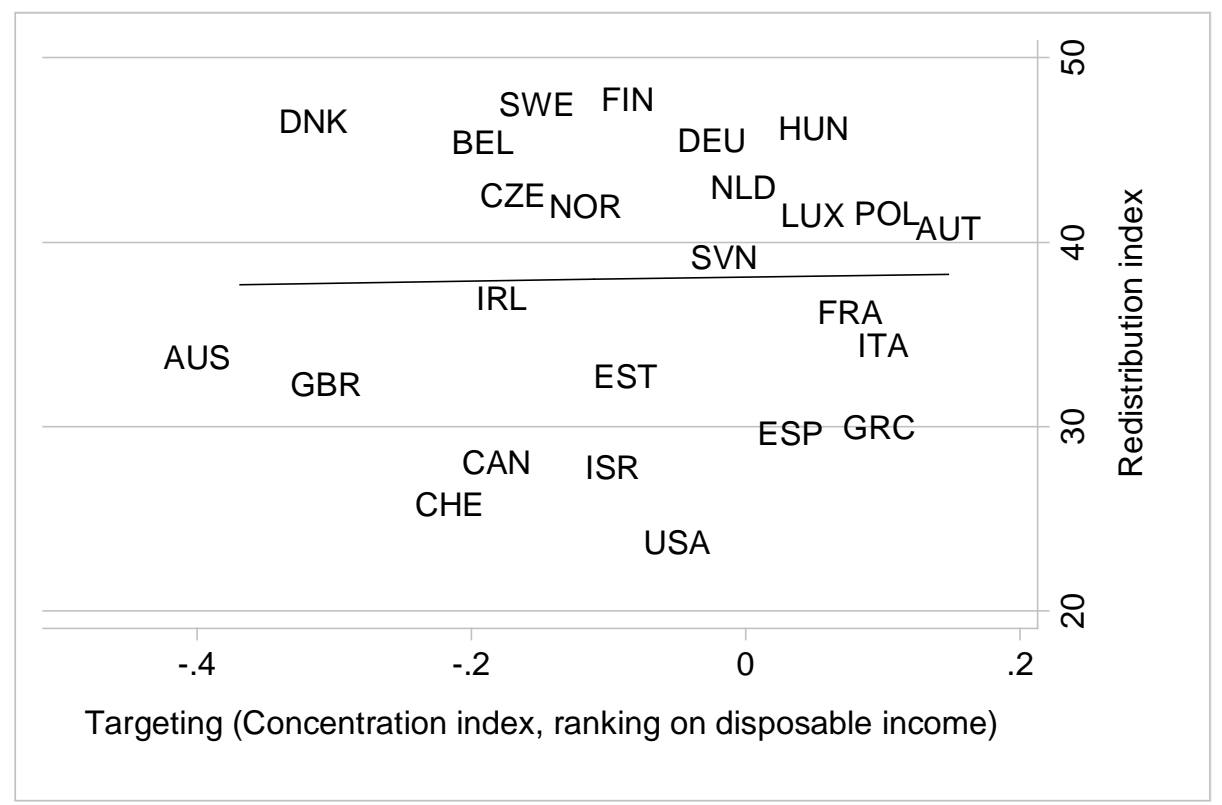

Note: for Belgium, France, Greece, Hungary, Slovenia and Spain calculations are based on disposable incomes instead of gross incomes due to data availability.

Source: Luxembourg Income Study

The picture is similar to the one based on gross incomes mainly due to two reasons. On the one hand, for some countries there is no information on taxes implying that gross income corresponds to disposable income in this analysis. On the other hand, taxes in general cause only little reranking of income units (in line with other results in literature), meaning that the relative contribution of an income unit's transfers to the concentration coefficient is hardly affected.

When ranking incomes on the basis of market income (Figure 13), all concentration coefficients turn to be negative, indicating that in all countries transfers are strongly pro-poor. Strongest pro-poorness is found in Australia, the Netherlands, the United Kingdom, Switzerland, and Denmark. According to this measure Estonia turns out to have the most universal system.

As already mentioned, these differences between ranking based on market income and gross income point to different degrees of reranking in countries. Reranking is very important in countries where many social transfer-recipients have a market income of zero. Take the case of the Netherlands. In the market income based approach this country has just about the most targeted transfer system; in the gross income based calculation, social transfers appear to be far more distributionally neutral. An important factor here is the relatively generous pension system in the Netherlands. In the market income based calculation it is effectively assumed that pensioners would have zero income in absence of the transfer. While this is clearly an unrealistic counterfactual, the market income based approach does say something about the extent to which transfers go to households solely reliant on them. 
Figure 13. Concentration index (ranking by market income) and redistributive impact

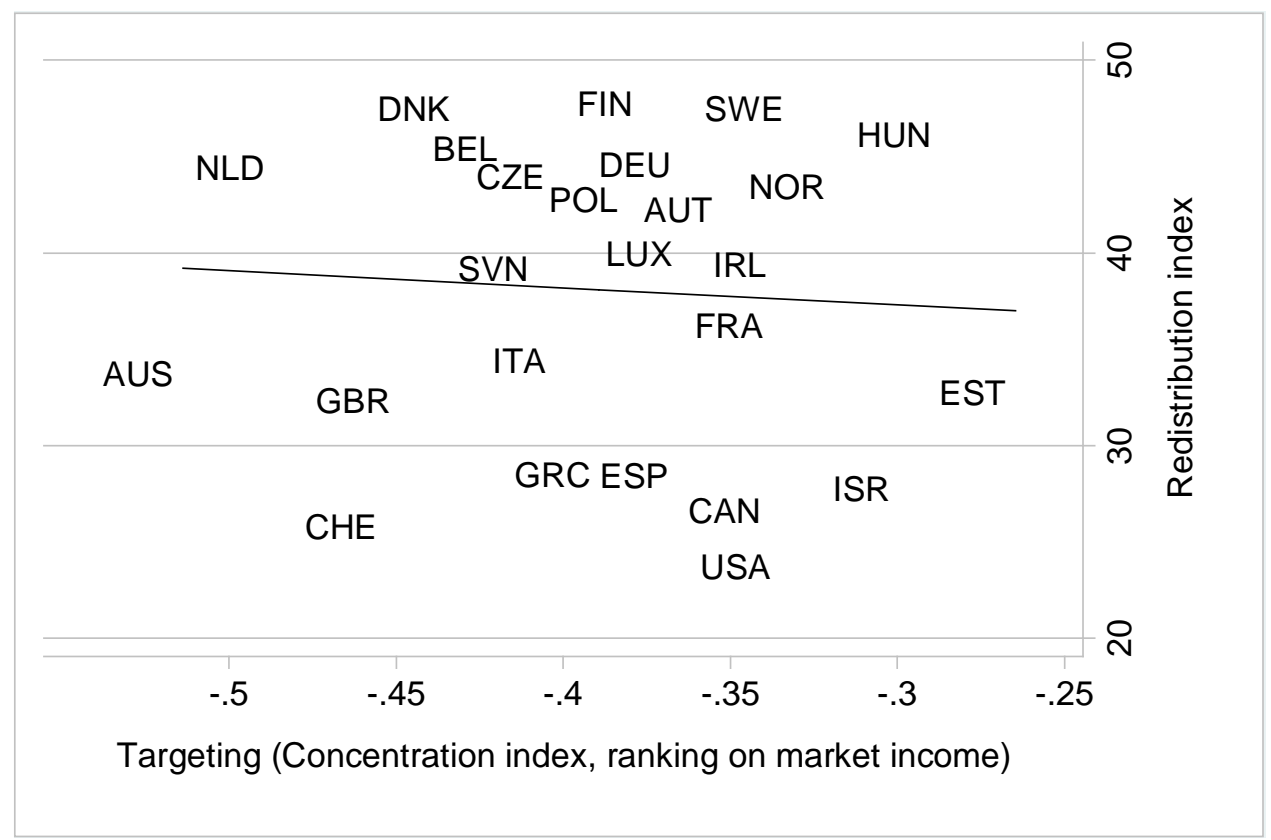

Note: due to data availability incomes are reported net of taxes for Belgium, Greece, Hungary, Slovenia and Spain; part of "gross" incomes are reported net of taxes for Italy and France.

Source: Luxembourg Income Study

\subsubsection{The role of taxes}

Not all LIS datasets include gross income amounts, implying that gross income in fact corresponds to disposable income and that market income does not include taxes. This is the case for seven countries in our analysis, namely Belgium, France, Greece, Hungary, Italy, Slovenia and Spain. This also implies that social transfers are net of taxes in these countries, whereas in the other countries gross transfers (i.e. before deduction of taxes) are used. The gap from the "net" countries is thus particularly big for the countries where transfers are subject to substantial taxation, as is the case in the Nordic countries. 
Figure 14. Concentration index (ranking by gross income) and redistributive impact, restricting the analysis to countries with full information on transfers and taxes

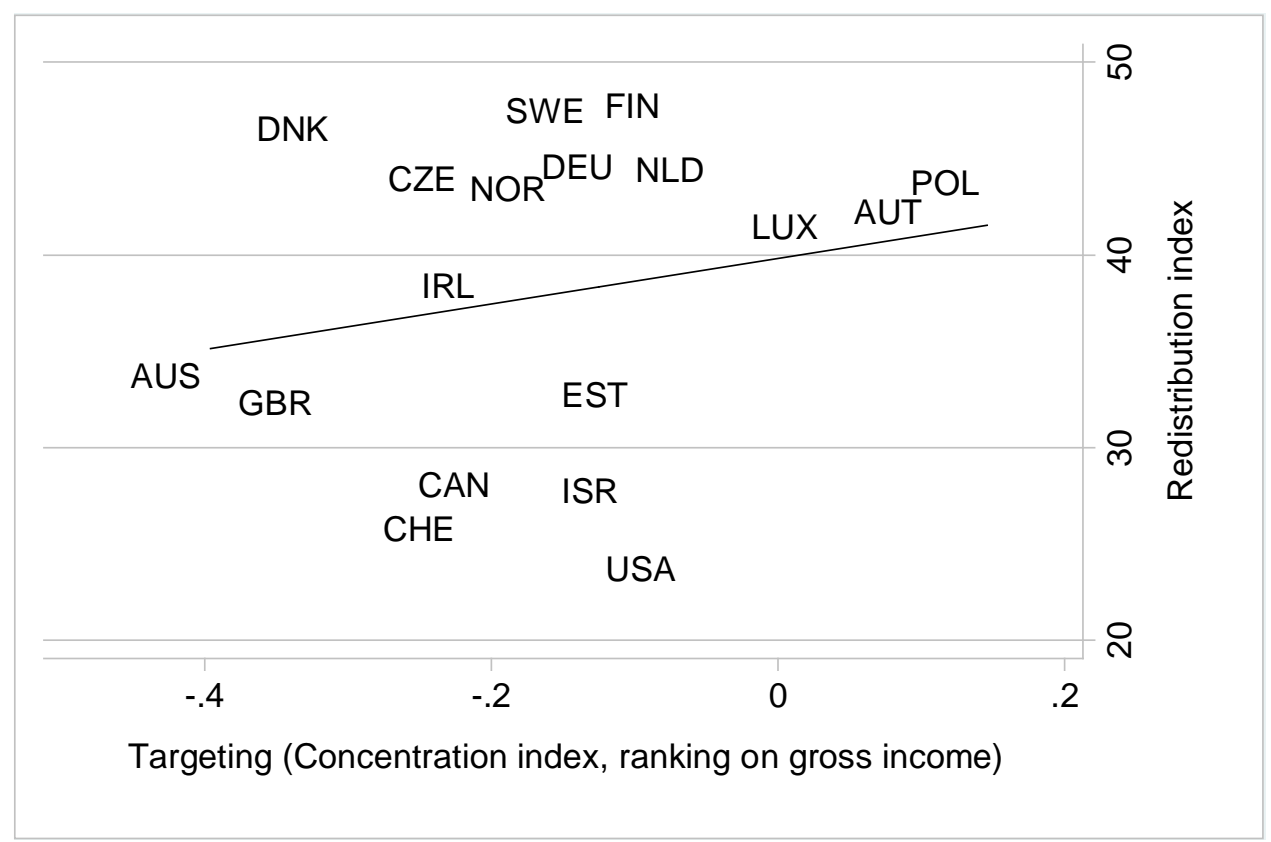

Source: own analysis using LIS data

Therefore we restrict the analysis to countries with a similar gross income concept. Figure 14 shows that the relationship between the extent of targeting and redistributive impact becomes a positive one, with countries on both ends of the targeting-universalism dimension essentially achieving similar levels of redistribution. This also highlights that the omitted countries (with the exception of Belgium), have positive concentration index values; focusing on these countries yields a negative relationship between targeting and redistribution. The question, though, remains if the nature of this negative relationship is related to certain system characteristics of the countries with positive concentration index values or is it due to the incomplete information on taxes. Overall, these results suggest that the difference between net and gross transfers may play an important role in the outcomes and merit further investigation.

\subsubsection{The effect of mandatory individual and occupational pensions}

In this section we trace the influence of mandatory individual and occupational pensions in more detail. The LIS data offers such information for most of our countries, except of Austria, the Czech Republic, Estonia, Spain, Greece, Hungary, Italy, Luxembourg, the Netherlands, Poland, and Slovenia.

Why care about the impact of occupational pensions? Two primary reasons prevail. First, the LIS database has recently underwent a major restructuring of its income variables. In the "old" LIS terminology, which is used in Korpi and Palme, as well as Kenworthy studies, social transfers do not include occupational pensions, as the latter income category is considered a part of market ("factor") income. This has changed in the new terminology, where occupational pensions are considered as long-term insurance transfers, and thus included in the list of social security transfers. Second, occupational pensions become an 
increasingly important income source, especially given that progressively more people reach the retirement age enabling the claim of the benefits. Hence, if less relevant in the past (when such schemes were introduced), it becomes a substantial source of the old-age income nowadays. For example, based on our calculations with LIS data, occupational pensions constitute on average from $2 \%$ to $6 \%$ of gross incomes (or up to one third of household received social transfers) in such non-EU countries, as Australia, Canada, Switzerland, the United States or Israel, and such EU-countries, as Denmark, France, Norway, Sweden or the United Kingdom. Occupational pension schemes are also ever more offered in countries, which previously did not use them. Based on Eichhorst et al. (2011), many EU pension system reforms are actually related to the introduction of the occupational pension schemes. This is seen as a potential response to counteract the projected decreases in the average gross public pension benefit and the average gross wage (or the benefit ratio). As such, methodological consequences related to classification of occupational pensions are more than a matter of pure taxonomy.

In the Kenworthy graph, the "old" typology is used. We replicate the graph in panel A of Figure 15 (see Appendix 2 for the original figure). Application of the "new" terminology implies a directional change, as shown in panel B of Figure 11. The main cause of this change is related to two factors. First, the distribution of the occupational pensions is either weakly pro-poor or even pro-rich. This contrasts with the strong or weak pro-poorness usually observed for the rest of the social transfers and hence has important implications on the overall distributional properties of social transfers. Second, the reclassification of occupational pensions affects the value and the distributional properties of market income too. For all countries of our analysis, the Gini coefficients of market income (which is used for calculation of the redistribution index) have increased following this re-classification pointing to the equalizing nature of occupational pensions if considered as market income. Consequently, the value of the redistribution index has increased. As such, the shift from the upward to the downward sloping relationship is influenced both by effects on the concentration and redistribution indices.

Figure 15. Social transfers inclusive of occupational pensions: concentration index (ranking by gross income) and redistributive impact, mid 2000s - "Kenworthy" selection of countries

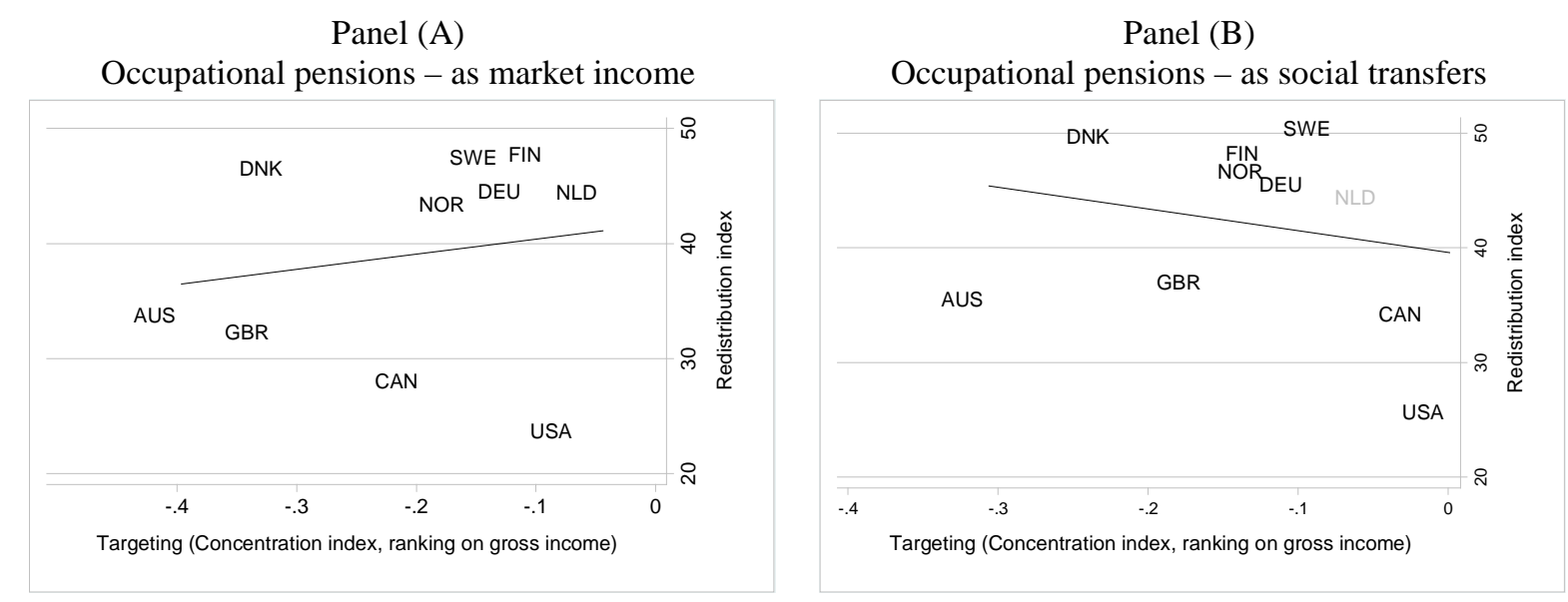

Note: countries with no information available on occupational pensions are in grey font.

Source: own calculations using LIS data 
Figure 16. Social transfers inclusive of occupational pensions: concentration index (ranking by gross income) and redistributive impact, mid 2000s - all countries

Panel (A)

Occupational pensions - as market income s

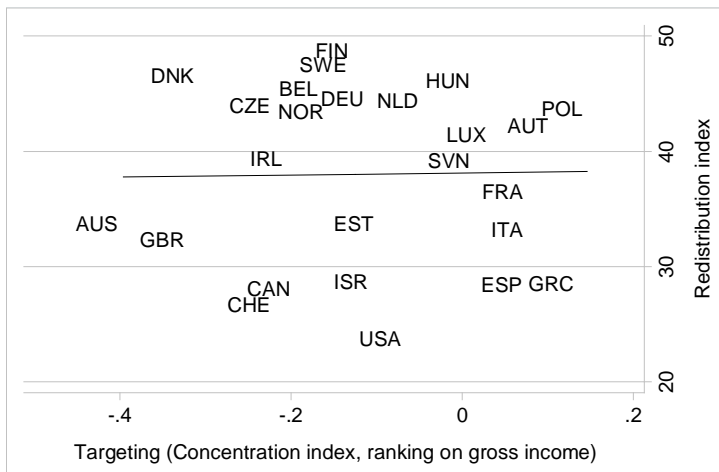

Panel (B)

Occupational pensions - as social transfers

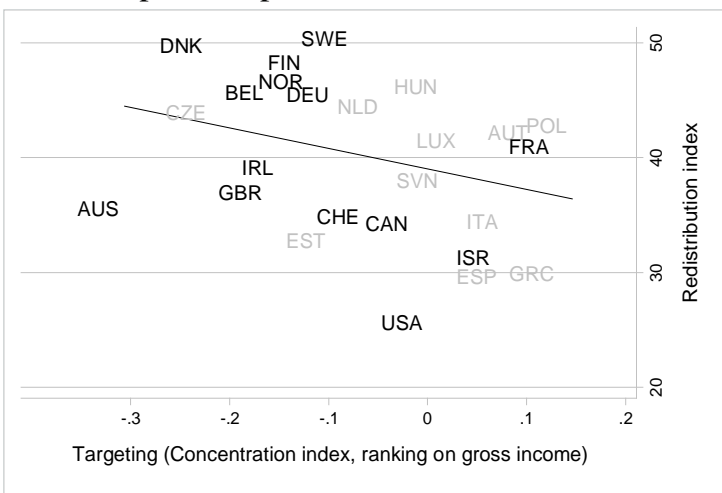

Note: due to data availability disposable instead of gross incomes are used for Belgium, Greece, Hungary, Slovenia and Spain; part of "gross" incomes are reported net of taxes for Italy and France; countries with no information available on occupational pensions are in grey font.

Source: own calculations using LIS data

Figure 16 repeats the message of Figure 15, but for all countries: if occupational pensions are treated as part of social security transfers, the relationship between targeting and redistribution becomes a negative one. A note of cautiousness is needed, though, here: this finding cannot be verified for all our countries due to the lack of information in the LIS data. The question, however, shows the importance of classification of social transfers and the role of the occupational pensions per se.

\subsubsection{Robustness for data source: LIS versus EU-SILC data}

Another important robustness check involves the one for data source. Figure 17 replicates the main analysis on the basis of EU-SILC 2005 data (the value of indices using LIS and EU SILC data can be found in Table A.1 of Appendix 3). As EU-SILC covers a different range of countries than the LIS data, we focus only on the countries that are available in both datasets. This implies that non EU-countries are excluded. All EU-SILC income types (e.g. gross income, social transfers) are aligned as close as possible to the methodological choices of the main part of our study on the basis of LIS data, though some differences are unavoidable due to the dataset specificities ${ }^{12}$. We discuss the latter issue below.

12 To ensure the highest degree of comparability between the two datasets, we derive own EU-SILC income lists in accordance to methodological choices of our main analysis. First, this implies, that our EU-SILC based gross incomes are somewhat different from the "original” (EUROSTAT derived) EU-SILC gross incomes. For example, we include private individual pensions, while this is not the case in the EUROSTAT list of gross incomes. Second, some income components are not traceable in EU-SILC and therefore cannot be correctly allocated to the LIS analogous income lists. For example, we can neither exclude occupational pensions from the old-age pensions' category in EU-SILC nor we are sure this is the actual income category of their allocation. Some other income types are not possible to identify in EU-SILC and thus to allocate correctly too. 
Figure 17. Concentration index (ranking by gross income) and redistributive impact in countries with information available both in LIS and EU SILC data
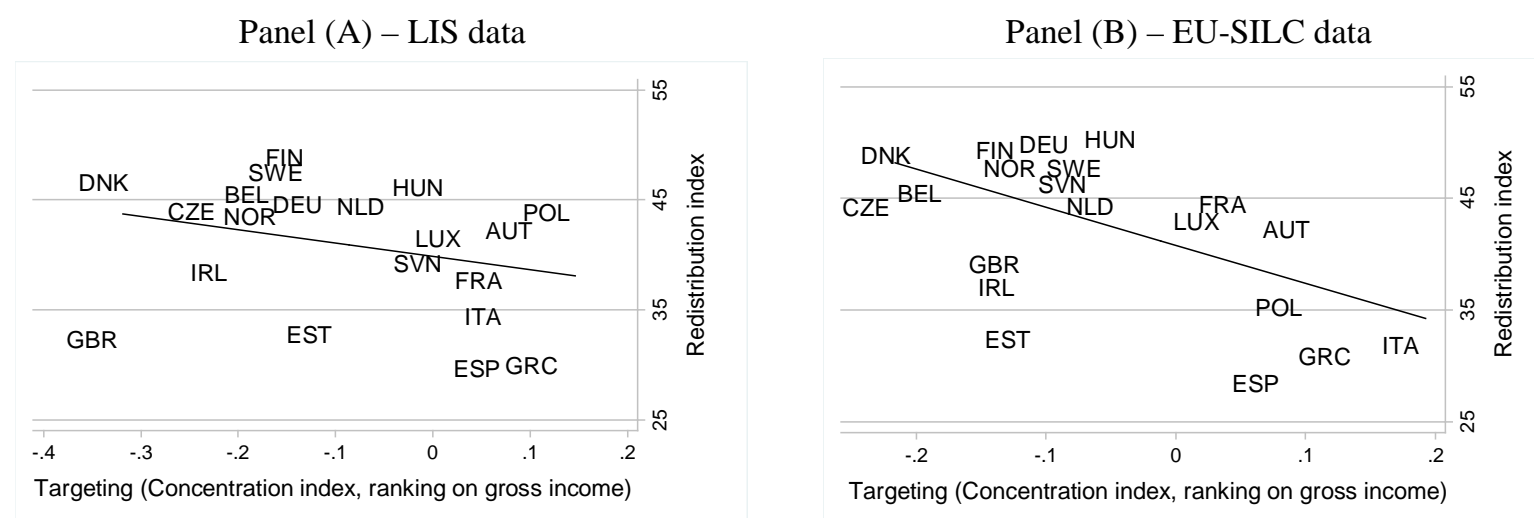

Note: due to LIS data availability disposable instead of gross incomes are used for Belgium, Greece, Hungary, Slovenia and Spain; part of "gross" incomes are reported net of taxes for Italy and France; in EU-SILC data, disposable instead of gross incomes are reported for Greece, Italy and Spain.

Source: own calculations using LIS and EU-SILC data

As shown by Figure 17, the relationship between targeting and redistribution using LIS data would remain rather unclear, though slightly downward sloping. The picture based on the EUSILC data is somewhat different: a clearer pattern appears indicating that the more targeted systems tend to be the most redistributive.

Furthermore, we also observe a denser positioning of the countries with respect to the $\mathrm{x}$ axis values. Especially, at the outer ends of the targeting dimensions we find relative consistency: the most targeted systems (Denmark, the Czech Republic and Belgium) achieve comparatively strong redistribution while the least pro-poor systems (Greece, Italy) have comparatively weak redistributive impacts. Conversely, a somewhat more widespread redistribution portrait is obtained with EU-SILC than with LIS data. For example, there are more countries with redistribution index at or higher than $45 \%$ in EU-SILC than in LIS data.

There are also some other striking differences of specific country outcomes based on EUSILC in comparison to LIS data:

- Italy takes a somewhat different position (more towards the "universalist" side of the spectrum although this is a clear misnomer in the Italian case, or for that matter the other south European countries). The southern European countries still remain important drivers of the negative relationship.

- The Czech Republic takes a striking position in having a strongly targeted and highly redistributive system. A similar, though less pronounced, move is observed for Belgium. Altogether, Denmark, the Czech Republic and Belgium appear as the most redistributive and the most targeted systems.

- The UK features as having a far less targeted system than in the LIS based analysis. Other countries show up as less targeted systems (e.g. Denmark, Sweden, Ireland), but to a lesser extent than the UK.

- Hungary and Slovenia appear as having the most redistributive systems, together with Sweden, whereas the redistributive power of Polish is recorded as much lower.

What are the major factors driving differing country positions when the EU-SILC data is used? Differences in classification of income and varying information sources are of primary 
importance, with the latter one being the major contributor. We depict this in Table 1, where values of concentration and redistribution indices are compared.

As noted before, LIS dataset information for some countries actually stems from national SILC surveys (see Appendix 1 for more information). We list these countries in the first half of Table 1. The comparison of concentration and redistribution indices for these countries proves that essentially the same results are obtainable from both datasets. In particular, the redistribution indices are close in their values. The surprising exceptions though concern the concentration indices for Spain and especially Ireland - they refer to large(r) data mismatches between the two datasets. Given that redistribution indices, which are based on distributional properties of market and disposable incomes, have no such biases for these two countries, our conclusion is that the list of social transfers is somewhat different for these two countries between the datasets - and thus affects the value of the derived concentration indices. This may concern, for example, the classification of occupational pensions.

For the countries with different data sources in EU-SILC and LIS, biases between the indices are much larger, in particular, for the concentration indices. Hence, this shows the importance of the choice of data source in explaining the relationship between targeting and redistribution. Not only differing data sources and income classifications play a role here, but, also differences in terms of the availability of no or only partial tax information. This applies to French, Hungarian, Italian and Slovenian data, pointing to the need of cautiousness when interpreting the results.

Table 1. Concentration (ranked on gross incomes) and redistribution indices in EU-SILC and "old" LIS data

\begin{tabular}{|c|c|c|c|c|c|c|c|}
\hline & \multirow[t]{2}{*}{$\begin{array}{l}\text { SILC survey } \\
\text { used in LIS }\end{array}$} & \multicolumn{2}{|c|}{ EU-SILC } & \multicolumn{2}{|c|}{ LIS } & \multicolumn{2}{|c|}{$\begin{array}{c}\text { Ratio } \\
\text { EU-SILC } \\
\text { / “old” LIS }\end{array}$} \\
\hline & & CI & $\mathrm{RE}$ & CI & RE & CI & $\mathrm{RE}$ \\
\hline \multicolumn{8}{|c|}{ Countries with SILC as the underlying information source in LIS data: } \\
\hline AUT & Yes & 0.11 & 42.304 & 0.11 & 42.255 & 1.00 & 1.00 \\
\hline CZE & Yes & -0.22 & 44.185 & -0.22 & 44.002 & 0.99 & 1.00 \\
\hline EST & Yes & -0.11 & 32.441 & -0.10 & 32.807 & 1.10 & 0.99 \\
\hline ESP & Yes & 0.09 & 28.503 & 0.08 & 29.686 & 1.13 & 0.96 \\
\hline FIN & Yes & -0.12 & 48.263 & -0.13 & 47.804 & 0.95 & 1.01 \\
\hline GRC & Yes & 0.14 & 30.883 & 0.13 & 29.987 & 1.04 & 1.03 \\
\hline IRL & Yes & -0.12 & 38.591 & -0.21 & 38.472 & 0.60 & 1.00 \\
\hline LUX & Yes & 0.04 & 42.973 & 0.03 & 41.516 & 1.09 & 1.04 \\
\hline NLD & Yes & -0.04 & 44.358 & -0.04 & 44.466 & 1.01 & 1.00 \\
\hline \multicolumn{8}{|c|}{ Other countries: } \\
\hline BEL & No & -0.18 & 46.871 & -0.16 & 45.485 & 1.09 & 1.02 \\
\hline$\overline{D E U}$ & No & -0.08 & 48.839 & -0.11 & 44.630 & 0.73 & 1.09 \\
\hline DNK & No & -0.2 & 48.946 & -0.31 & 46.612 & 0.65 & 1.05 \\
\hline FRA & No & 0.06 & 43.406 & 0.08 & 37.730 & 0.76 & 1.15 \\
\hline GBR & No & -0.12 & 39.118 & -0.32 & 32.385 & 0.36 & 1.21 \\
\hline HUN & No & -0.03 & 50.326 & 0.02 & 46.217 & -1.64 & 1.09 \\
\hline ITA & No & 0.19 & 31.865 & 0.08 & 34.456 & 2.51 & 0.92 \\
\hline NOR & No & -0.10 & 47.739 & -0.16 & 43.490 & 0.67 & 1.10 \\
\hline POL & No & 0.10 & 35.315 & 0.15 & 42.829 & 0.70 & 0.82 \\
\hline SWE & No & -0.05 & 49.088 & -0.13 & 47.568 & 0.41 & 1.03 \\
\hline SVN & No & -0.06 & 46.310 & 0.02 & 39.259 & $\begin{array}{l}-4.18 \\
\end{array}$ & 1.18 \\
\hline
\end{tabular}

Note: ratios in bolded font point to larger than $10 \%$ differences between the indices.

Source: own calculations using EU-SILC and LIS data 


\section{Discussion: making sense of the disappearing paradox}

The disappearance of the negative relationship between targeting and redistributive impact as established by Korpi and Palme is driven by two factors. First, as Kenworthy (2011) has already demonstrated, the observed relationship for the original set of countries in the Korpi and Palme study has weakened over time. This raises the question: what has changed in those countries? Second, and arguably more crucially, it is the inclusion of new countries that causes the relationship to become a very weak one. This raises a second major question: what is different about the countries which did not feature in the original analysis ?

\subsection{Has the nature of targeting changed?}

The Korpi and Palme argument essentially is about the relative size of the electorates benefiting from and paying for redistributive measures. The studies by Moene and Wallerstein and by others explicitly test theoretical models that seek to explain varying attitudes to universal versus selective systems in terms of their pure redistributive impacts across electorates, particularly the middle class (for an overview see McCarthy and Pontusson, 2009).

From this perspective it is not easy to understand why, for example, the United States has shifted towards a more universalist position. Perhaps an explanation is to be found in the fact that the debates that triggered and shaped social policy changes over the 1990s and 2000s were less about such distributional issues than about the perceived effects of strongly targeted redistributive policies.

One of the factors that arguably made some targeted systems less politically robust and prone to spending cuts in the 1980s was the fact that strongly targeted, particularly means-tested benefits entailed strong work disincentives and other behavioural incentives. The issue was not so much that these systems catered to a small part of the electorate, far removed from the median voter and that for this reason they suffered from relative neglect by politicians.

Quite to the contrary, means-tested systems that catered to the poor were at the heart of political debates. In the United States, the main means-tested system (AFDC) became the focus of quite heated political debates during the 1980s. Charles Murray's Losing Ground (1984) launched a virulent attack on this final safety net provision as it was then in place. That system was identified as the main culprit in creating an underclass of chronically welfare dependent single mothers. While the book and its claims became the object of equally virulent criticism from the left, welfare reform took centre stage in the political debate. Clinton ran his first campaign in a slogan to 'end welfare as we know it'.

What ensued was a major shift in social policy. Statutory time limits on social assistance benefit duration were introduced. This move was accompanied by the expansion of a targeted benefit of an altogether different nature: the Earned Income Tax Credit. The Earned Income Tax Credit (EITC) had been introduced in the US in 1975 as an exemption from employees' social security payments for poor working households with children. The system was subsequently expanded and the 1993 reform in particular turned the scheme into the country's pre-eminent anti-poverty program for families of active working age. The expansion of EITC was accompanied by the introduction of new training and employment schemes and several 
increases in the minimum wage. This combination represented a paradigmatic shift in American social policy. Empirical studies show that the expansion of EITC, in combination with other policy reforms and several increases in the minimum wage, produced some striking initial results, including marked increases in labour market participation and declines in poverty among some segments of the population, especially single-parent households (Hotz and Scholz, 2003; Eissa and Hoynes, 2004).

The EITC has become America's pre-eminent welfare programme. Spending has increased and appears to enjoy relatively broad and robust political support. This raises the question why this it. The system is less strongly targeted than before, which probably in part accounts for the shift of the US in the graphs. The system now caters to larger sections of the electorate, including the (lower) middle class, and this may account for that expansion. But an equally if not more important factor may be the fact that the system is perceived to encourage and reward work; it enjoys greater overall legitimacy and that may explain why spending on EITC has risen dramatically (Kenworthy, 2011).

Activation and the prevention of long-term dependence among able-bodied people at active age has also became a major issue in Europe and an increased policy emphasis on activation has become evident, certainly at the level of policy rhetoric, and gauging by some indicators also in terms of actual policy (Barbier and Ludwig-Mayerhofer 2004; Kenworthy, 2008; Dingeldey, 2007; Eichhorst and Konle-Seidl, 2008, Aurich, 2009; Immervoll, 2010; Marchal and Van Mechelen, 2013). That said, the truth is that we still lack reliable indicators of actual activation intensity, mainly because implementation aspects are so difficult to measure (e.g. effective sanctioning or effective availability and take-up of training places, subsidized jobs etc.). To reduce work disincentives, earnings disregards have been introduced for people dependent on social assistance or unemployment benefits who make a (partial) transition from complete benefit dependency to part-time work. People on targeted benefits have also become the focus of intensified monitoring, activation and sometimes sanctioning efforts (Marx and Nelson, 2012).

Most importantly, perhaps, means-tested benefits are no longer exclusively aimed at people not in work, but also at those in work in low-paid jobs. The French RsA scheme is a good example of a new style means-tested benefit scheme that offers integrated support for the nonemployed and (part-time) low paid workers alike. The scheme also has entirely different work incentives. The RSA (Revenu de Solidarite Active), was introduced in France in 2008 the specific aim of remodelling the incentive structure of people on social assistance, and particularly to make work or returning to education a more lucrative financial prospect. The previous minimum income system (Minimum Integration Income - RMI) was based on a one for one trade-off of benefit for earned income, so that EUR 100 earned led to a deduction of EUR 100 from benefit paid. Under RSA a "62\% slope" is applied so that earning EUR 100 leads to a EUR 38 deduction in benefit paid. Efforts have also been made to encourage beneficiaries of RSA into employment, for example with assisted employment contracts and (improved) insertion mechanisms. In addition, the RSA has simplified the provision of social protection by combining several previously separate schemes into a single sum. A household with no earned income is eligible for the "basic RSA" while the "in-work RSA" acts as a topup for people with low earnings.

The point here is that targeted, means-tested systems look totally different today from the systems in place in the 1980s. Whereas the old systems were the focus of harsh welfare 
critiques, especially from the right, the new targeted systems are lauded as the essential gateways of welfare to work.

\subsection{What makes the newly included countries different?}

The original Korpi and Palme analysis included Australia, Canada, Finland, France, Germany, the Netherlands, Norway, Sweden, Switzerland, the United Kingdom and the United States. The additional countries included in our LIS based analysis roughly fall into three categories: a) three Southern European countries (Greece, Italy, Spain); b) post-communist countries now part of the EU (Czech Republic, Estonia, Hungary and Slovenia) and c) advanced economies not included in the original analysis: Austria, Ireland, Israel and Luxembourg.

The southern European countries included in our analysis - Greece, Spain and Italy - drive much of the observed weak positive relationship between targeting and redistributive impact. In terms of the targeting measure used in this study the southern European countries rank as having the least amount of targeting. Looking at the share of transfers going to the bottom quintile of the income distribution (ranked by gross income), the targeting coefficient even underestimates the pro-richness of the transfers there (Figure A5). In the LIS based analysis, the share going to the bottom quintile in Italy, Greece and Spain is just over 10 per cent. This is three times less than the 35 per cent of transfers flowing to the poorest in the countries with the highest concentration coefficients: the UK, Denmark and Australia.

A distinct feature of the southern European welfare systems is a high degree of categorical differentiation, mostly by occupational category. This is referred to as "dualistic social insurance" (Ferrera, 2010). While some segments of the population, and particularly the workforce, are relatively well catered for, other segments essentially receive little or nothing. Having co-evolved with a highly segmented, breadwinner biased labour markets, the southern European welfare states exhibit a strong degree of internal segmentation: generous benefits for core/regular workers, modest benefits for peripheral/irregular workers (what Jessoula et al. (2003) call the 'mid-siders') and meagre entitlements, if any at all, for those with no formal labour market attachment. There is a sizeable literature showing that welfare systems there tend to reinforce or at least replicate socio-economic and occupational inequalities (Ferrera, 2010; Matsaganis et al., 2003). The southern European countries also remain relatively unique among the "old" European countries in not having nationally organized social safety nets, except in Portugal where it was introduced in 1997. In Italy and Spain social assistance remains a regional matter and benefit levels vary quite considerably (Van Mechelen and Marchal, 2012).

It must be noted, however, that the continuing prevalence of multi-generational households and family solidarity transfers in the South raises particular methodological issues for the present analysis. Pensions, for example, play an important role in the household income packages of the working aged, including children (Vandenbroucke et al, 2013). However, to what extent the assumption of full and fair sharing in such households holds is unclear.

The four post-communist economies take strikingly varying positions on the two main dimensions under focus here. In the LIS based analysis, the Czech Republic appears to have a relatively targeted system while Poland is to be found on the other end of the spectrum; 
redistributive impacts, however, are very similar in both countries. (Note that market income inequality remains comparatively low in the Czech Republic, but high in Hungary or Poland.)

We observe these countries at one point in time, capturing their current position in ongoing trajectories of change. After the collapse of the Soviet Union these countries experienced a major transition shock, marked by massive labour shedding and declining wages. (The Czech Republic, a country that takes a marked position in these analyses, but also in other comparative studies on inequality and poverty in relation to welfare state spending, was less affected.) A number of CEE governments implemented targeted safety nets and expanded pensions, unemployment and family benefits, be it in an ad hoc way, and driven to some extent by organised interests (Cook, 2010). As the 1990s progressed many CEE started to restructure their welfare states, taking a turn towards liberalization. The extent and intensity of liberalization differed, however, with countries like the Czech Republic maintaining the most solidaristic welfare provision. Hungary and Poland did embark on the path of liberalisation while the Baltic states, initially strongly affected by the transition, first lagged and then took the most radical turn towards market-conforming reforms. Universal subsidies and family benefits, for example, were partially replaced by means-tested benefits targeted at the poor. Concurrently, there has been a partial return to pre-communist Bismarckian traditions. For example, financing of pensions and social insurance was moved from state budgets to payroll taxes. Mandatory capitalized pillars were added to pay-as-you-go pension systems.

At present, there is a considerable degree of diversity among the post-socialist countries and it is important to underscore the point that these do not belong to a singular 'regime'. This diversity is also evident from measures of social spending, taxation and benefit generosity (Cerami and Vanthuysse, 2010; Cook; 2010). Institutional indicators of minimum income protection also point to very significant differences (Van Mechelen \& Marchal, 2012; Goedemé, 2012). It is also clear that parts of welfare systems there remain in a state of flux (Marx and Nelson, 2013).

\section{Conclusion}

This paper has re-examined Korpi and Palme's influential claim that "the more we target benefits at the poor, the less likely we are to reduce poverty and inequality". We find that this tenet no longer holds as a robust empirical generalisation. This paper has replicated their original analysis for a broad set of rich countries and finds that by and large the relationship between targeting and redistributive impact is a very weak one across countries, suggesting that the extent of targeting per se may not matter as much as we have assumed since Korpi and Palme. For what it matters, targeting tends to be associated with higher levels of redistributive impact, especially when overall effort in terms of spending is high.

A key point of this paper, however, is that empirical specification, data source and country selection matter in very significant ways - and this perhaps holds a lesson for comparative welfare state research in a wider sense.

The point of departure for this paper has been Korpi and Palme's original empirical specification so as to achieve maximum initial comparability When applying this methodology, i.e. exactly replicating the original study for more recent years, we find that the relationship looks totally different today, with countries taking very diverse positions on both the targeting and the redistribution dimensions. No clear relationship appears across countries. 
Some countries, notably Denmark, have transfers systems that are strongly targeted at the poor and yet yield strong redistributive impacts, contrary to the original Korpi and Palme thesis. At the other end the picture looks equally diverse, if not more so. Weak targeting is in some cases clearly associated with relatively weak redistributive impacts. The best performing countries in terms of redistributive impact employ 'targeting within universalism”. But this in itself is no guarantee for strong redistribution: quite a number of countries that target in equal measure, but not necessarily with the same level of spending effort, have poorly performing systems in terms of redistributive impact.

As indicated, outcomes are to some extent sensitive to operationalisation, data source and, especially, country selection. These matter to varying degrees.

The choice of the ranking variable does matter to some extent, as others have also demonstrated, but not in a way that substantially changes the picture. Ranking by market income instead of gross income yields stronger redistributive effects, because households, like pensioners, solely reliant on transfers are assumed to have zero market incomes in the absence of transfers. This produces stronger redistributive impacts almost by definition.

Rather more substantially relevant is the fact that the categorisation of income components matters. It is striking that the picture shifts in a significant way once occupational pensions are treated as transfers rather than as part of market income. In view of the extent of state regulation and in some cases support of occupational pensions a good case can be made that these are more properly seen as transfers than as market income. If we do so, stronger targeting tends to be associated with a larger redistributive impact.

It also matters whether we consider transfers in total or whether instead we do the analysis at a more disaggregated level. A decomposition analysis shows that the relationship between targeting and redistribution is different for family transfers as compared to old-age benefits, or other benefits for the working aged. Only for family benefits do we still find a weak negative relationship between targeting and redistributive impact. The spread of countries is quite considerable however.

Another striking sensitivity result is the comparison between LIS and SILC. Analysis on the SILC data clearly yields a picture strongly suggestive of a positive relationship between targeting and redistributive impact. This is in part because countries covered in both datasets take different positions in some cases. Different country positionings are due to three major factors: differences between the data sets in the way incomes are classified, differences in the the underlying data sources, and the inclusion or exclusion of tax information.

Finally, there is the key issue of country selection. The fact that the relationship originally established by Korpi and Palme breaks down is due to two factors. First, the countries originally included in the study have shifted their position. Second, and more important, there is now data available for a far larger set of countries. It is the addition of these new data points which causes the relationship to break down completely.

We have tried to make substantive sense of this breakdown of this by focusing on two questions: a) what may have changed in the countries originally included in the analysis; b) in what respect are welfare states now additionally included different? The key issue underlying both questions is this: what does this mean for what we think to know about the dynamics of political support for welfare programmes. Can programmes that cater in a targeted way to 
relatively small segments of the electorate maintain sufficient political support so that they do not become "poor”, i.e. underfunded programmes?

Recall that the Korpi and Palme argument essentially is about the relative size of the electorates benefiting from and paying for redistributive measures. We have argued here that the debates that triggered and shaped social policy changes over the last decades were less about such distributional issues than about the incentive effects of redistributive policies. The issue was not so much that strongly targeted systems catered to a small part of the electorate, far removed from the median voter. The political weakness rather derived from the perceived work and family formation incentives. Nowadays strongly targeted (means-tested) benefits are no longer exclusively aimed at people not in work, but also at those in work in low-paid jobs. Whereas the old systems were the focus of harsh critiques, especially from the right, the "new" targeted systems (for example EITC in the US, RSA in France or WTC in the UK) are lauded as the essential gateways of welfare to work. These systems enjoy relatively broad and robust political support.

Another part of the answer lies in the fact that we now have data for a larger set of countries. The Southern European countries drive much of the observed positive relationship between targeting and redistributive impact. The post-socialist countries take quite varying positions on both the targeting and the redistribution dimensions. Interestingly, all countries with positive concentration indices were missing in the original Korpi and Palme study, effectively limiting the range of observations from countries with strong targeting to countries with weak targeting.

This paper raises further questions. Why does a similar degree of strong targeting, as captured by the concentration index, produce stronger redistributive outcomes in Denmark as compared to the United Kingdom and Australia? More broadly the question is: why are similar levels of targeting associated with different redistributive outcomes across countries? Our analysis also points to the potentially dissimilar impact of targeting across different types of transfer provisions, for example child benefits as compared to pensions. To what extent all this is a result of our modelling choices, of compositional factors (e.g. the distribution of beneficiaries across the income spectrum) or actual design features of systems is still to be established. We have also brought to light that the impact of taxes, both in general and specifically those on transfers, requires further exploration.

As we already indicated, the redistributive outcomes of a particular system are dependent on the characteristics of the underlying population, in terms of socio-demographic composition, the extent of market income inequality and other such factors, etc. A system may appear as very targeted in its outcomes, even if its design does not include means-testing or needs-based features. This means that strictly speaking we cannot derive from the concentration coefficient how the pro-poorness of a transfer comes about. Here we need to take further steps. Using a tax-benefit model like EUROMOD, we could go further in analyzing how system design features matter relative to (or in interaction with) contextual features in producing redistributive impacts. 


\section{References}

Allan, J. P., \& Scruggs, L. (2004). Political Partisanship and Welfare State Reform in Advanced Industrial Societies. American Journal of Political Science, 48(3), 496-512.

Alvarez P.B., (2001), 'The Politics of Income Inequality in the OECD: The Role of Second Order Effects', LIS-working paper, No. 284, 29p.

Atkinson A., (1993), 'Work Incentives', in A.B. Atkinson and G.V. Mogensen (eds.), Welfare and Work Incentives: A North European Perspective, Clarendon Press, Oxford.

Aurich, P. (2009), "Levels, directions and divisions of change towards activation in Europe", ISA World Congress 2010, RC 19.13 ,Comparing Activation Models and Policy', July 11-17, Gothenburg, Sweden.

Baldwin P., (1990), The Politics of Social Solidarity: Class Bases of the European Welfare State 1875-1975, Cambridge University Press, Cambridge.

Bandelj \& Mahutga (2010). How Socio-Economic Change Shapes Income Inequality in PostSocialist Europe. Social Forces, Vol. 88, No. 5, pp. 2133-2162.

Barr N., (1998), The Economics of the Welfare State, Oxford University Press, Oxford.

Barbier, J.-C. and Ludwig-Mayerhofer, W. (2004) 'Introduction: the many worlds of activation', European Societies, Vol. 6, No. 4, pp. 423-36.

Barth, E and Moene, K. (2009) The Equality Multiplier. NBER Working Paper 15076. Cambridge Massachusetts: National Bureau of Economic Research.

Beramendi Alvarez, P. (2001) The Politics of Income Inequality in the OECD. The Role of Second Order Effects. Luxembourg Income Study Working Paper No. 284.

Bergh, (2005), 'On the Counterfactual Problem of Welfare State Research: How Can We Measure Redistribution?’, European Sociological Review, 21 (4), 345-357.

Borck, Rainald. 2007. “Voting, Inequality and Redistribution.” Journal of Economic Surveys 21(1): 90-109.

Brady, David and Rebekah Burroway. "Targeting, Universalism and Single Mother Poverty: A Multi-Level Analysis Across 18 Affluent Democracies." Demography 49 (2012): 719-746.

Bradley, D., Huber, E., Moller, S., Nielsen, F., \& Stephens, J. D. (2003). Distribution and redistribution in postindustrial democracies. World Politics, 55(02), 193-228

Brooks, C., \& Manza, J. (2006). Social Policy Responsiveness in Developed Democracies. American Sociological Review, 71(3), 474-494.:

Cantillon B., Marx I., Van den Bosch K., (2003), 'The puzzle of egalitarianism: relationship between employment, wage inequality, social expenditure and poverty’, European Journal of Social Security, 5(2), p. 108-127.

Cerami, A. and Vanhuysse, P. (eds), Post-Communist Welfare Pathways. Theorizing Social Policy Transformations in Central and Eastern Europe, Basingstoke: Palgrave Macmillan: 164-180

Cook, L. (2010), 'Eastern Europe and Russia’, in Castles, F et al. (eds) Oxford Handbook of the Welfare State; Oxford: Oxford University Press 
Corak, M., Lietz, C. and Sutherland H. (2005) The Impact Of Tax And Transfer Systems On Children In The European Union, EUROMOD Working Papers EM4/05, EUROMOD at the Institute for Social and Economic Research

Corcoran, S. and Evans, W.N. (2010) Income Inequality, the Median Voter, and the Support for Public Education. NBER Working Paper 16097. Cambridge Massachusetts: National Bureau of Economic Research.

Deleeck, H. et al. (1983) Het Matteüseffect. De ongelijke verdeling van de sociale overheidsuitgaven in België. Antwerpen: Kluwer.

Dingeldey, I. (2006), 'Between workfare and enabling- Different Paths to Transformation of the Welfare State: A comparative analysis of activating labour market policies', in European Journal of Political Research 46 (6): 823-851.

Eichhorst, Werner., Gerard, M., Kendzia, M., Mayrhuber, C., Nielsen, C., Rünstler, G. and Url, T. (2011), 'Report No. 42: Pension Systems in the EU - Contingent Liabilities and Assets in the Public and Private Sector', IZA Research Report No 42.

Eichhorst, W. and Konle-Seidl, R. (2008), Contingent Convergence: A comparative analysis of activation policies, IZA DP 3905

Eissa, N. and Hoynes, H. (2004) 'Taxes and the Labor Market Participation of Married Couples: The Earned Income Tax Credit’, Journal of Public Economics 88: 1931-1958.

European Commission (2013), Communication to the European Parliament, the Council, the European Economic and Social Committee and the Committee of the Regions, Towards Social Investment for Growth and Social Cohesion - including implementing the European Social Fund 2014-2020, COM (2013) 83 final

EUROSTAT (2007). 'EU-SILC User Database Description Version 2007-1 from 01-03-09', European Commission, EUROSTAT; Luxembourg.

Ferrera, M. (2010), 'The South European Countries', in Castles, F et al. (eds) Oxford Handbook of the Welfare State; Oxford: Oxford University Press

Ferrarini, T., Nelson, K. And Höög, H. 'From universalism to selectivity: old wine in new bottles for child benefits in Europe', in Marx, I., Nelson, K. eds. (2012), Minimum Income Protection in Flux, Basingstoke: Palgrave Macmillan

Figari, F., Paulus, A. and H. Sutherland (2011), 'Measuring the size and impact of public cash support for children in cross-national perspective', Social Science Computer Review 29(1), 2011

Forma, P. (1997) 'The Rational Legitimacy of the Welfare State: Popular Support of ten Income Transfer Schemes in Finland', Policy and Politics, Vol. 25, No.3, 235-249.

Förster, M. and Mira d'Ercole, M. (2005) Income Distribution and Poverty in OECD Countries in the Second Half of the 1990s. OECD Social Employment and Migration Working Papers, No. 22. Paris: Organisation for Economic Co-operation and Development.

Fuchs, M. (2009) 'Social assistance - no, thanks? The non-take-up phenomenon and its patterns in Austria, Germany and Finland after 2000'. European Centre Policy Brief September 2009. Vienna: European Centre.

Goedeme, T. 'Minimum income protection for Europe's elderly. What and how much has been achieved', in Marx, I., Nelson, K. eds. (2012), Minimum Income Protection in Flux, Basingstoke: Palgrave Macmillan 
Goodin R., (1988), Reasons for Welfare: The Political Theory of the Welfare State, Princeton University Press, Princeton.

Goodin R., LeGrand J., (1987), Not Only the Poor; The Middle Classes and the Welfare State, Unwin Hyman, London.

Horn, Daniel. 2011a. “Income Inequality and Voter Turnout.”GINI Discussion Papers no. 16.

Hotz, V.J. and Scholz, J. K. (2003) 'The Earned Income Tax Credit', in R. Moffit (ed) Meanstested Transfer Programs in the U.S.. University of Chicago Press.

Jäntti, M., Kangas, O. And Ritakallio, V. (1996) 'From Marginalism to Institutionalism: Distributional Consequences of the Transformation of the Finnish Pension Regime', Review of Income and Wealth, Vol. 42, No. 4, pp. 473-491.

Jessoula, M., Granziano, P. R., \& Madama, I. (2010). 'Selective Flexicurity' in Segmented Labour Markets: The Case of Italian 'Mid-Siders'. Journal of Social Policy, 39(4), 561583.

Jesuit, D. K. and Mahler, V. A. (2010). Comparing Government Redistribution Across Countries: The Problem of Second-Order Effects. Social Science Quarterly, 91: 1390 1404.

Kakwani, N. (1977a), "Measurement of tax progressivity: an international comparison”, in Economic Journal, vol. 87, pp.71-80.

Kangas, O. (1995) 'Attitudes on Means-Tested Social Benefits in Finland', Acta Sociologica, Vol. 38, Issue 4, pp. 299-310.

Kenworthy, L., \& Pontusson, J. (2005). Rising Inequality and the Politics of Redistribution in Affluent Countries. Perspectives on Politics, 3(03), 449-471. :

Kenworthy, L. (2008) Jobs with Equality, Oxford: Oxford University Press

Kenworthy, L. (2011) Progress for the Poor. Oxford: Oxford University Press (forthcoming)

Korpi, W. (1980) 'Social Policy and Distributional Conflict in the Capitalist Democracies. A Preliminary Comparative Framework’, West European Politics, Vol. 3, No. 3, pp. 296316.

Korpi, W. and Palme, J. (1998) 'The Paradox of Redistribution and Strategies of Equality: Welfare State Institutions, Inequality, and Poverty in the Western Countries', American Sociological Review, Vol. 63, No. 5 ,p. 661-687.

Lambert, P. (2001), The Distribution and Redistribution of Income, Third Edition, Manchester University Press.

Larsen, C. (2008) 'The Institutional Logic of Welfare Attitudes. How Welfare Regimes Influence Public Support', Comparative Political Studies, Vol. 41, No.2,pp. 145-168.

Lindbeck A., Nyberg S., Weibull J., (1999), "Social Norms and Economic Incentives in the Welfare State”, Quarterly Journal of Economics, 114(1): 1-35.

Lindert, P.H. (2004) Growing Public: Social Spending and Economic Growth since the Eighteenth Century. Cambridge: Cambridge University.

Mahler, V. A. (2008), Electoral turnout and income redistribution by the state: A crossnational analysis of the developed democracies. European Journal of Political Research, 47: 161-183. 
Marx, I., Nelson, K. eds. (2013), Minimum Income Protection in Flux, Basingstoke: Palgrave Macmillan

Matsaganis, M., Ferrera, M., Capucha, L., \& Moreno, L. (2003). Mending Nets in the South: Anti-poverty Policies in Greece, Italy, Portugal and Spain. Social Policy and Administration, 37(6), 639-655.

McCarty, N. and Pontusson, J. (2009) 'The Political Economy of Inequality and Redistribution', in W. Salverda, B. Nolan and T. Smeeding (eds) Oxford Handbook of Economic Inequality. Oxford: Oxford University Press.

Meltzer, A. and Richard, S. (1981) A rational theory of the size of government. Journal of Political Economy, Vol. 89, No. 5, pp. 914-927.

Merton, R. (1968) 'The Matthew effect in science', Science, Vol. 159, No. 3810, pp. 56-63.

Milanovic, B . (2000). "The Median-Voter Hypothesis, Income Inequality and Income Redistribution.” European Journal of Political Economy 16(2-3): 367-410.

Moene, K. and Wallerstein, M. (2001) 'Inequality, Social Insurance and Redistribution', American Political Science Review, Vol. 95, No. 4,pp. 859-874.

Moene K., Wallerstein M., (2002), 'Income Inequality and Welfare Spending: A Disaggregated Analysis’, Unpublished paper. North-western University, Evanston, IL, February.

Moene, K. and Michael Wallerstein, M. (2003) 'Earnings Inequality and Welfare Spending', World Politics, Vol. 55, No. 4, pp485-516.

Murray, C. (1984), Losing ground: American social policy, 1950-1980, New York: Basic Books.

Nelson, K. (2004). Mechanisms of poverty alleviation. Journal of European Social Policy, 14, 371-390.

Nelson, Kenneth (2007). "Universalism versus Targeting: The Vulnerability of Social Insurance and Means-Tested Minimum Income Protection in 18 Countries, 1990-2002." International Social Security Review 60: 33-58.

Nolan, B. and Marx, I. (2008) 'Poverty and Social Exclusion', in W. Salverda, B. Nolan and T. Smeeding (eds) Oxford Handbook of Economic Inequality. Oxford: Oxford University Press.

OECD, (2004), OECD Employment Outlook 2004, OECD Publications, Paris.

OECD (2008) Growing Unequal: Income Distribution and Poverty in OECD Countries. OECD Publications, Paris.

OECD (2011) Divided we Stand. Why Inequality Remains Rising. OECD Publications Paris.

Olivera, Javier 2012 Preferences for redistribution in Europe Gini Discussion Paper No 67

Okun A.M., (1975), Equality vs Efficiency: The Big Trade-Off , Brookings Institution Press, Washington D.C.

Pierson, P. (1994) Dismantling the Welfare State? Reagan, Thatcher, and the Politics of Retrenchment. Cambridge: Cambridge University Press.

Ringen S., (1987), The Possibility of Politics, Clarendon Press, Oxford. 
Skocpol, T. (1991). Targeting within universalism: Politically viable policies to combat poverty in the United States. In C. Jencks \& P. E. Peterson (Eds.), The urban underclass (pp. 411-436). Washington, DC: The Brookings Institution.

Scruggs L., (2004), Welfare State Entitlements Data Set: A Comparative Institutional Analysis of Eighteen Welfare States, Version 1.1. Beschikbaar op: http://www.sp.uconn.edu/ scruggs/wp.htm.

Titmuss, R. (1969), Essays on the Welfare State, second edition with a new chapter, London: Unwin University Books.

Toth, I., Horn, D. and M. Medgyesi (2013), Rising inequalities: will electorates go for higher redistribution, forthcoming in Salverda et al. (eds), OUP.

Vandenbroucke, F, Diris, R., Verbist, G. (2013), Excessive social imbalances and the performance of welfare states in the EU, mimeo

Van Kerm, P. (2009), 'sgini: Generalized Gini and Concentration coefficients (with factor decomposition) in Stata', v1.0, CEPS/INSTEAD, Differdange, Luxembourg.

Van Lancker Wim, Ghysels Joris, Cantillon Bea.- An international comparison of the impact of child benefits on poverty outcomes for single mothers Antwerpen: , 2012.- 28 p. (CSB working paper/University of Antwerp, Herman Deleeck Centre for Social Policy ; 12/03)

Van Mechelen, N., and J. Bradshaw (2013), 'Child Poverty as a Government Priority: Child Benefit Packages for Working Families, 1992-2009', in I. Marx, and K. Nelson (2012), Minimum Income Protection in Flux. Basingstoke: Palgrave Macmillan.

Van Mechelen, N., and S. Marshal (2013), 'Struggle for Life: Social Assistance Benefits, 1992-2009', In I. Marx, and K. Nelson (eds.), Minimum Income Protection in Flux. Basingstoke: Palgrave Macmillan. Macmillan.

Van Oorschot, W. (2002) 'Targeting Welfare: on the Functions and Dysfunctions of Meanstesting in Social Policy' in P. Townsend and D. Gordon (Eds.), World Poverty: New Policies to Defeat an Old Enemy. Bristol: The Policy Press.

Verbist, G. (2004) Redistributive Effect and Progressivity of Income Taxes: An International Comparison across the EU using EUROMOD, EUROMOD Working Paper EM5/04, The Microsimulation Unit, Cambridge University.

Whiteford, Peter (2007) "Targeting, Redistribution, and Poverty Reduction in OECD Countries." Unpublished.

Whiteford, Peter (2008) "How Much Redistribution Do Governments Achieve? The Role of Cash Transfers and Household Taxes." Chapter 4 in Growing Unequal? Paris: OECD

Whiteford, Peter (2009) "Transfer Issues and Directions for Reform: Australian Transfer Policy in Comparative Perspective." Unpublished. Social Policy Research Center, University of New South Wales. 


\section{Appendix 1- Comparing LIS and EU-SILC datasets}

The EU-SILC data is collected using a common framework across the participating European countries and therefore encompasses a high degree of survey (design) comparability. The LIS data (i.e. the Luxembourg Income Study Database) is a harmonised microdata with the underlying information sources variable across the participating countries. As shown in a table below, LIS data for a number of our countries (i.e. Austria, Estonia, Greece, Spain, Ireland, etc.) is derived from the national EU-SILC surveys - seemingly, the most common type of LIS information source for the European countries as of mid 2000's. The other frequent source of information is household budget surveys (e.g. France, Poland, Slovenia), as well as diverse income and expenditure surveys. LIS data for Denmark is derived from the income tax register data.

Table 1. Sources of information for LIS data

\begin{tabular}{|c|c|c|c|c|}
\hline & $\begin{array}{c}\text { EU-SILC } \\
(2005)\end{array}$ & $\begin{array}{c}\text { HBS } \\
(2004-2005)\end{array}$ & $\begin{array}{c}\text { Register data } \\
(2004)\end{array}$ & $\begin{array}{c}\text { Other surveys } \\
(200-2005)\end{array}$ \\
\hline Countries & $\begin{array}{c}\text { AUT, EST, GRE, ESP, } \\
\text { CZE, IRL, LUX, NLD, } \\
\text { FIN* }\end{array}$ & FRA, POL, SVN & DNK & $\begin{array}{c}\text { BEL, DEU, HUN, } \\
\text { ITA, SWE, GBR, } \\
\text { NOR }\end{array}$ \\
\hline
\end{tabular}

* Finnish SILC is included in the collection of the national survey "Income distribution survey (IDS)"

Source: http://www.lisdatacenter.org/

Given that LIS and EU-SILC have the same information sources for some of their countries, any analysis based on one or the other dataset should essentially yield the same for the latter countries. Some differences are, however, likely to occur. For example, imputation policy is different across the two databases. LIS does not implement own imputations, whereas there is a requirement to "impute missing values in the income variables where that can be reasonably done" for the EU-SILC data (EUROSTAT, 2007). Furthermore, classification of incomes is somewhat different across the two datasets. The table below presents the structure of gross and disposable incomes in the LIS and EU-SILC data in more detail and highlights differences in individual income components.

In general, the broadest income categories are essentially the same in both datasets and concern employment, capital incomes or private transfers. Larger differences, though, lie in the classification of smaller income components, making comparisons of certain income types, as social transfers, between the two datasets cumbersome. We give an example using the old-age pension classification.

The EU-SILC refers to "old-age benefits" as all types of benefits (i.e. disability, survivor, retirement pensions) if paid to a person after a (country specific) standard retirement age. The original identification of the benefit payment (i.e. due to disability) is not kept when pooling information under old-age benefits. A different income typology is applied in LIS data. Here, transfers are classified by type (i.e. universal, assistance, insurance based) and need (i.e. oldage, disability, unemployment, education, etc.), but without a reference to a person's age. Hence, "old-age pensions", an EU-SILC term of social transfers, is not directly obtainable in 
the LIS data ${ }^{13}$. Similar classification divergences to the ones of "old-age pensions" are noted for the other types of social transfers, such as disability pensions, family allowances, or unemployment benefits.

Table 2. Composition of gross and disposable incomes in EU-SILC and LIS databases

\begin{tabular}{|c|c|c|c|c|}
\hline & & EU-SILC & & LIS \\
\hline \multirow{18}{*}{$\frac{\vdots}{11}$} & + & Gross employee cash or near cash income & \multirow{2}{*}{+} & \multirow{2}{*}{$\begin{array}{l}\text { Regular and casual (monetary and non-monetary) paid employment } \\
\text { income }\end{array}$} \\
\hline & + & Company car (not in 2005) & & \\
\hline & + & $\begin{array}{l}\text { Gross cash benefits or losses from self-employment, } \\
\text { including royalties }\end{array}$ & + & $\begin{array}{l}\text { Self-employment income (farm and non-farm: profit from business } \\
\& \text { household production activities) }\end{array}$ \\
\hline & + & $\begin{array}{l}\text { Interests, dividends, profit from capital investments } \\
\text { in unincorporated business (minus associated } \\
\text { expenses); }\end{array}$ & \multirow[t]{2}{*}{+} & \multirow{2}{*}{$\begin{array}{l}\text { Capital income: interest and dividends, voluntary individual } \\
\text { pensions, rental income, royalties (minus interest paid). }\end{array}$} \\
\hline & + & $\begin{array}{l}\text { Income from rental of a property or land (minus } \\
\text { associated expenses); }\end{array}$ & & \\
\hline & + & Old-age benefits & \multirow{3}{*}{+} & \multirow{3}{*}{$\begin{array}{l}\text { Assistance benefits: general social assistance; old-age } \\
\text { /disability/survivors assistance pensions; unemployment assistance; } \\
\text { family/maternity/child assistance; education, housing, heating, food } \\
\text { and medical assistance. }\end{array}$} \\
\hline & + & Housing allowances & & \\
\hline & \multirow{2}{*}{+} & \multirow{2}{*}{ Social exclusion not elsewhere classified } & & \\
\hline & & & \multirow{5}{*}{+} & \multirow{5}{*}{$\begin{array}{l}\text { Work-related insurance transfers: mandatory individual, } \\
\text { occupational, employment-related public and work-injury } \\
\text { pensions; sickness wage, maternity/parental wage, work-injury } \\
\text { wage and unemployment wage replacement. }\end{array}$} \\
\hline & + & Unemployment benefits & & \\
\hline & + & Disability benefits & & \\
\hline & + & Sickness benefits & & \\
\hline & \multirow[t]{2}{*}{+} & \multirow[t]{2}{*}{ Family/children related allowances } & & \\
\hline & & & \multirow[t]{3}{*}{+} & \multirow{3}{*}{$\begin{array}{l}\text { Universal benefits: old-age/disability/survivors universal pensions; } \\
\text { unemployment universal benefits; disability universal benefits; } \\
\text { family/child universal benefits; education-related universal benefits }\end{array}$} \\
\hline & + & Survivor' benefits & & \\
\hline & + & Education-related allowances & & \\
\hline & + & Regular inter-household cash transfers received & + & $\begin{array}{l}\text { Private transfers: merit-based education \& regular cash and non- } \\
\text { cash inter-household transfers; transfers from non-profit } \\
\text { institutions }\end{array}$ \\
\hline & + & Income received by people under age 16 & & \\
\hline \multirow{3}{*}{ 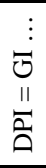 } & - & $\begin{array}{l}\text { Tax on income: at source plus tax-adjustments- } \\
\text { repayment/receipt on income \& social insurance } \\
\text { contributions }\end{array}$ & - & $\begin{array}{l}\text { Income taxes and social security contributions: tax withholdings \& } \\
\text { adjustments; social security contributions }\end{array}$ \\
\hline & - & Regular taxes on wealth & & \\
\hline & - & Regular inter-household cash transfers paid & & \\
\hline
\end{tabular}

Source: LIS and EU-SILC datasets

The two datasets also have a different treatment/reference of/to certain income components. For example, in EU-SILC gross incomes include monetary receipts by people under the age of 16. This income type does not exist in LIS. In the latter dataset, on the other hand, income from household production activities is viewed as self-employment income and included in household gross incomes. EU-SILC excludes this income type in the derivation of gross and disposable income types. The same applies to voluntary private pensions, which is not (yet) included in the calculation of total household gross and disposable incomes in EU-SILC. The LIS data refers to voluntary individual pensions as a type of capital income and includes it in the concepts of both gross and disposable incomes. Finally, disposable income in both datasets is calculated by subtracting withholding income taxes and tax adjustments, as well as social contributions. In the EU-SILC, however, further subtractions are also made: regular taxes on wealth and regular inter-household cash transfers paid. Though observed in the LIS

13 The EU-SILC equivalent category of old-age pensions has been created in the LIS data for some of the countries that derive their LIS information from the EU-SILC survey. 
data (e.g. such income types as property/municipality taxes, other direct taxes, interhousehold transfers paid), these expenditure types are not used in deriving disposable income.

To what extent these differences in gross and disposable income structures influence their monetary values? Below, we provide a quick comparison of average household incomes (nonequivalised and unweighted) across the countries that derive their information from the EUSILC survey and across the countries with diverging data information sources. For the first group of countries, any observed differences should be mainly due to differences in terminology and data provider's imputations. For the second group of countries, an information source can add an additional explanatory power in the observed differences.

\begin{tabular}{|c|c|c|c|c|c|c|c|c|}
\hline & \multicolumn{2}{|c|}{ Obs., \# } & \multicolumn{3}{|c|}{ GI (mean),EUR } & \multicolumn{3}{|c|}{ DPI (mean), EUR } \\
\hline & SILC & LIS & SILC & LIS & SILC/LIS & SILC & LIS & SILC/LIS \\
\hline \multicolumn{9}{|c|}{ Countries with the EU-SILC as a common information source: } \\
\hline AUT & 5148 & 5147 & 45186 & 45220 & 1.00 & 33606 & 33946 & 0.99 \\
\hline EST & 4169 & 4155 & 7315 & 7465 & 0.98 & 6060 & 6284 & 0.96 \\
\hline GRE* & 5568 & 5568 & n.a. & 19519 & n.a. & 18329 & 19026 & 0.96 \\
\hline ESP & 12937 & 12996 & n.a. & 21720 & n.a. & 21405 & 21977 & 0.97 \\
\hline $\mathrm{CZE}$ & 4351 & 4351 & 9200 & 9204 & 1.00 & 7643 & 7686 & 0.99 \\
\hline FIN & 11229 & 11229 & 49442 & 49258 & 1.00 & 35501 & 36127 & 0.98 \\
\hline IRL & 6085 & 6085 & 42239 & 41957 & 1.01 & 35234 & 35293 & 1.00 \\
\hline LUX & 3622 & 3622 & 69332 & 70619 & 0.98 & 54861 & 56750 & 0.97 \\
\hline NLD & 9356 & 9356 & 48513 & 48199 & 1.01 & 32378 & 32540 & 1.00 \\
\hline \multicolumn{9}{|c|}{ Other countries: } \\
\hline DEU & 13106 & 11294 & 41853 & 47927 & 0.87 & 31433 & 35229 & 0.89 \\
\hline DNK & 5957 & 83349 & 66793 & 54521 & 1.23 & 43035 & 37015 & 1.16 \\
\hline FRA** $^{* *}$ & 9754 & 10240 & n.a. & 32394 & n.a. & 30273 & 30674 & 0.99 \\
\hline ITA** & 22032 & 8012 & n.a. & 32271 & n.a. & 28520 & 24500 & 1.16 \\
\hline HUN* & 6927 & 2035 & 8407 & 7335 & 1.15 & 6666 & 7335 & 0.91 \\
\hline SWE & 6133 & 16268 & 46740 & 57355 & 0.81 & 31853 & 40809 & 0.78 \\
\hline SVN* $^{*}$ & 8287 & 3725 & 27269 & 16554 & 1.65 & 20543 & 16554 & 1.24 \\
\hline GBR & 10826 & 27753 & 48583 & 43061 & 1.13 & 36267 & 34441 & 1.05 \\
\hline NOR & 5991 & 13131 & 70310 & 68609 & 1.02 & 52385 & 51914 & 1.01 \\
\hline
\end{tabular}

Notes: * = "net" datasets in LIS; **= "mixed" dataset in LIS; GI = gross income; DPI = disposable income; mean = mean income; SILC/LIS = ratio of EU-SILC mean estimate over a LIS mean estimate. obs., \# = number of households; n.a. = data is not available, as information on gross incomes is missing.

We, actually, find no major differences in the two income estimates - average gross and disposable household incomes - between the LIS and EU-SILC datasets for the countries that rely on the SILC survey to draw their data. This implies that methodological differences between the datasets do not cause any significant deviations in income estimates. One should note, though, that this observation is made for the major aggregate income types as gross and disposable incomes, while larger deviations can be possible for the other income types or estimates.

The picture is very different for the remaining countries: a divergent data information source implies that highly varying income levels are observed between the EU-SILC and LIS datasets. Actually, only two countries, namely France and Norway, have income estimates, which are very close in their values. In Germany and Sweden, EU-SILC records both higher gross and disposable incomes than LIS, with an extreme gap (more than 20 percentage points) for Swedish disposable incomes. For Denmark, Slovenia and UK, EU-SILC provides higher mean values both for gross and disposable incomes. This difference is extremely large in the 
Slovenian case. This is partially explained by the fact that LIS collects only net incomes for Slovenia, whereas EU-SILC provides with the "true" gross information. Nonetheless, aside the issue of taxation, the difference in Slovenian disposable income is very high across the two datasets. Hungarian data is also reported "net" in LIS dataset, making it difficult to compare to gross incomes of the EU-SILC. Hungarian disposable incomes are higher in LIS dataset. Overall, this comparison of gross and disposable income shows that divergent income estimates when obtained from the two datasets are mainly due the diverging underlying information sources rather than to somewhat different classification of gross and disposable incomes. 


\section{Appendix 2 - “Original” studies}

Figure A.1: Index of Targeting of Transfer Income and Income Redistribution: 11 OECD countries, mid 1980s

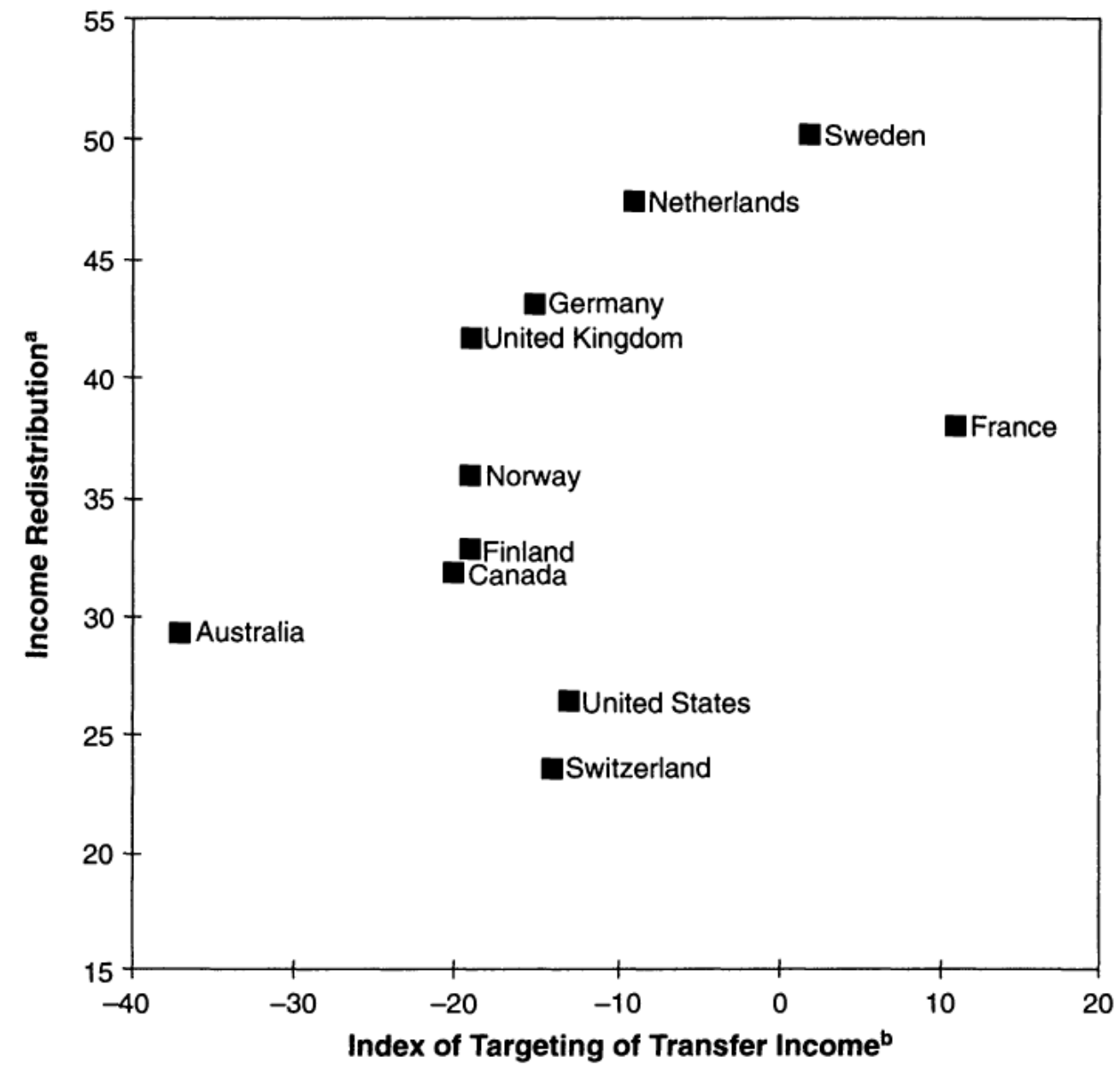

Source: Korpi and Palme, 1998. 
Figure A.2: Redistribution by targeting-universalism: across countries at common points in time
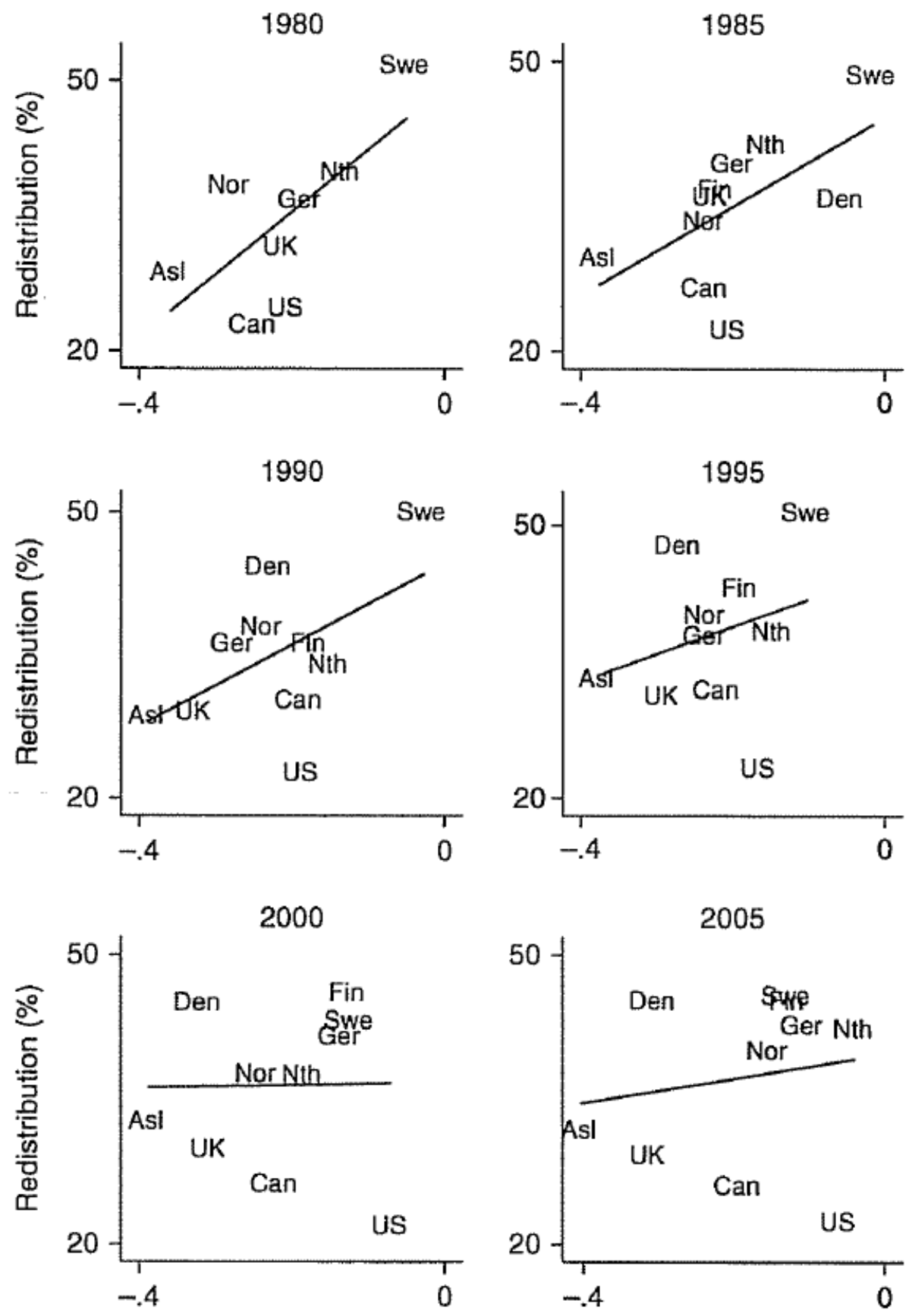

Targeting ......... Universalism

Targeting Universalism

Source: Kenworthy, 2011. 


\section{Appendix 3 - Other sensitivity checks}

Figure A.3. Reduction in inequality due to taxes and transfers compared with size of social transfers (cash social spending expressed as a share of GDP), mid 2000s.

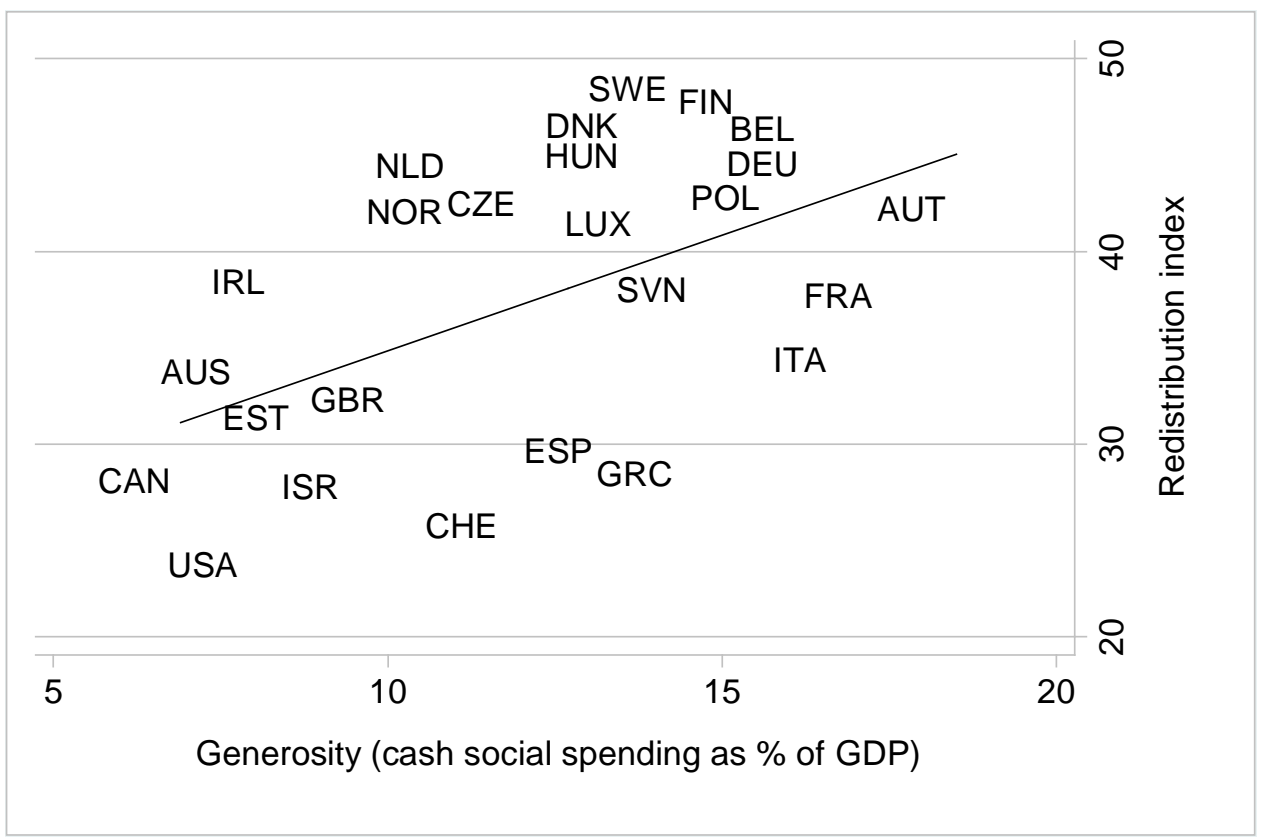

Source: OECD SOCX 2005 for cash social spending as a share of GDP.

Figure A.4. Targeting and generosity (cash social spending as \% of GDP), mid 2000s.

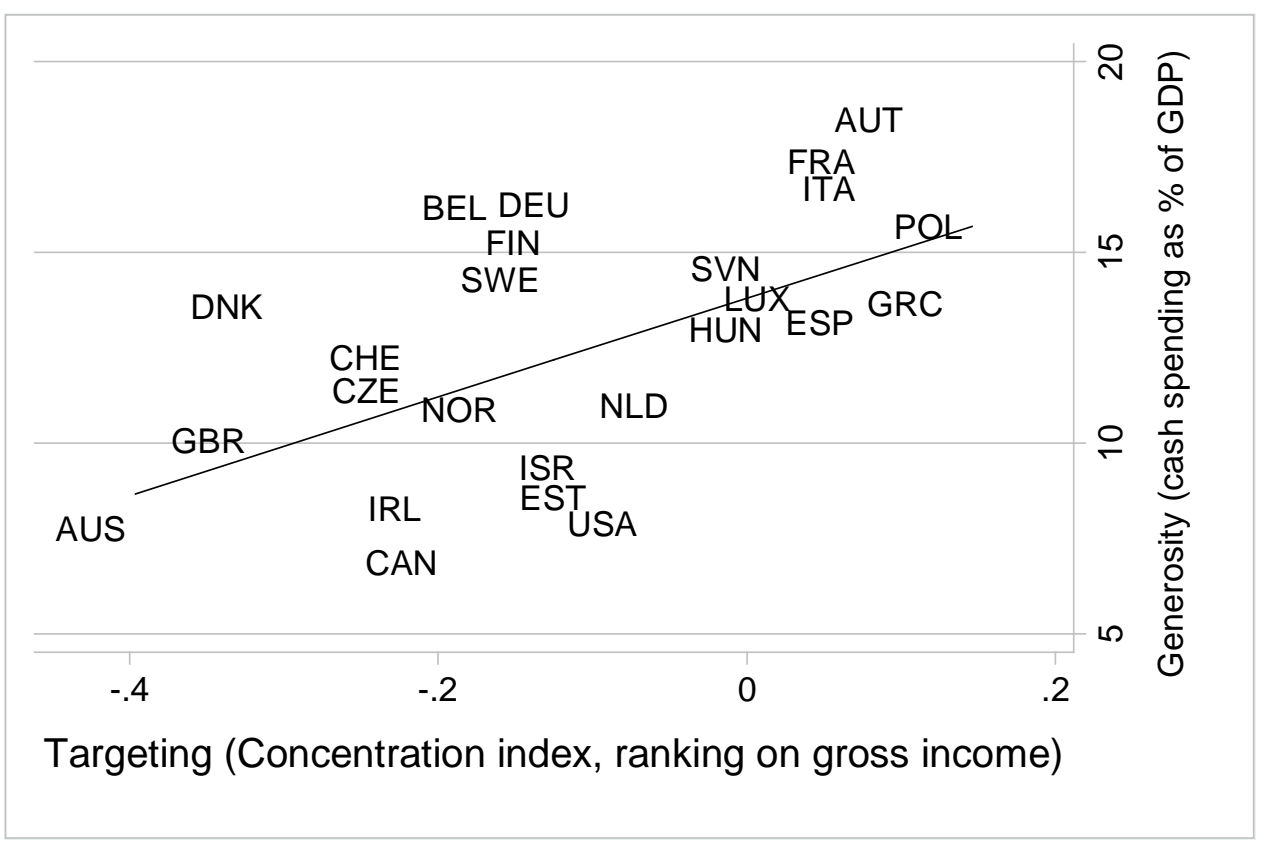

Source: OECD SOCX 2005 for cash social spending as a share of GDP. 
Figure A.5. Concentration coefficients versus bottom quintile transfers share

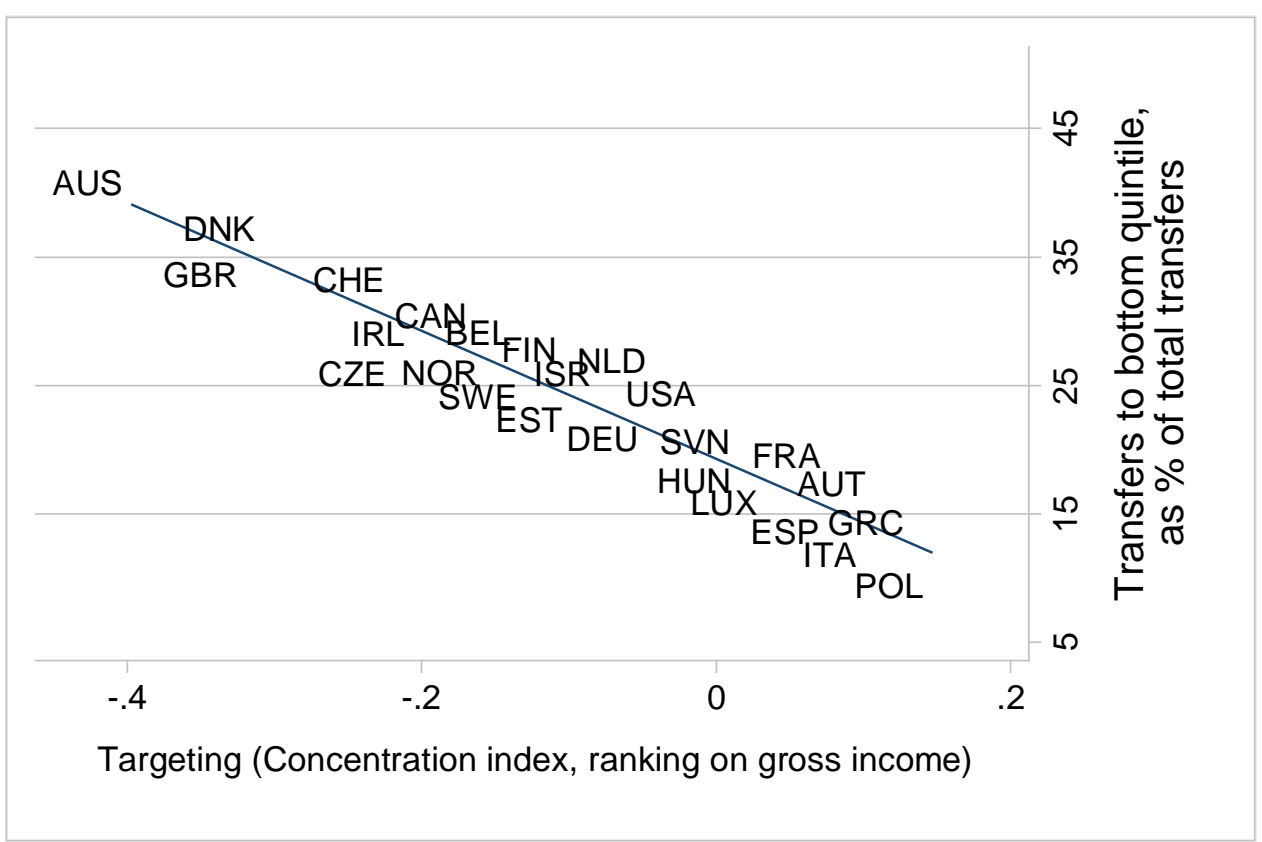

Source: own calculations using LIS data

Figure A.6. Concentration indices when ranked by gross and market income

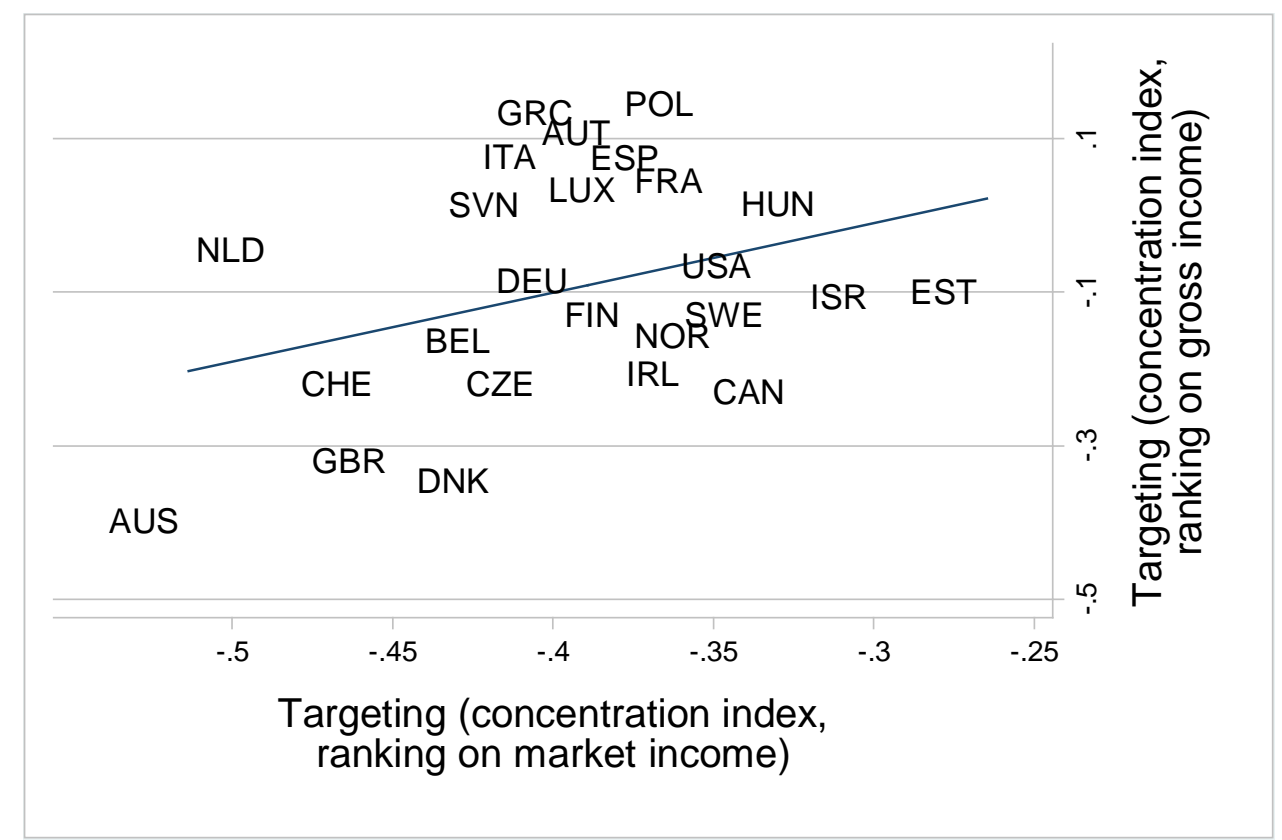

Source: own calculations using LIS data 
Table A.1: Gini coefficients and indices of redistribution, generosity and targeting, LIS and EU-SILC data, mid 2000s

\begin{tabular}{|c|c|c|c|c|c|c|c|c|c|c|c|c|c|}
\hline \multirow[b]{2}{*}{ Country } & \multicolumn{3}{|c|}{ GINI of income } & \multirow{2}{*}{$\begin{array}{c}\mathrm{RE} \\
(\mathrm{MI}-\mathrm{DI}) / \mathrm{MI} \\
\end{array}$} & \multirow{2}{*}{$\begin{array}{c}\text { Generosity } \\
\text { ST as \% of GI }\end{array}$} & \multirow{2}{*}{$\begin{array}{c}\text { Targeting } \\
\mathrm{CC}(\mathrm{GI}) \\
\end{array}$} & \multirow[b]{2}{*}{ Country } & \multicolumn{3}{|c|}{ GINI of income } & \multirow{2}{*}{$\begin{array}{c}\mathrm{RE} \\
(\mathrm{Ml}-\mathrm{DI}) / \mathrm{Ml}\end{array}$} & \multirow{2}{*}{$\begin{array}{l}\text { Generosity } \\
\text { ST as \% of GI }\end{array}$} & \multirow{2}{*}{$\begin{array}{c}\text { Targeting } \\
\mathrm{CC}(\mathrm{Gl}) \\
\end{array}$} \\
\hline & $\mathrm{Ml}$ & $\mathrm{Gl}$ & $\mathrm{DI}$ & & & & & $\mathrm{Ml}$ & $\mathrm{GI}$ & $\mathrm{DI}$ & & & \\
\hline AUS (2003) & 0.4723 & 0.3598 & 0.3126 & 33.8 & $11.4 \%$ & -0.3963 & & & & & & & \\
\hline AUT & 0.4648 & 0.3029 & 0.2684 & 42.3 & $26.7 \%$ & 0.1081 & AUT & 0.4652 & 0.3028 & 0.2684 & 42.3 & $26.7 \%$ & 0.1081 \\
\hline BEL (2000) & 0.5149 & 0.2807 & 0.2807 & 45.5 & $25.6 \%$ & -0.1622 & BEL & 0.5082 & 0.3187 & 0.2700 & 46.9 & $22.1 \%$ & -0.1760 \\
\hline CAN & 0.4416 & 0.3554 & 0.3173 & 28.1 & $10.9 \%$ & -0.1937 & & & & & & & \\
\hline CHE & 0.3545 & 0.2624 & 0.2629 & 25.8 & $11.8 \%$ & -0.2179 & & & & & & & \\
\hline CZE & 0.4768 & 0.3053 & 0.267 & 44.0 & $20.8 \%$ & -0.2177 & CZE & 0.4789 & 0.3056 & 0.2673 & 44.2 & $20.9 \%$ & -0.2162 \\
\hline DEU & 0.5028 & 0.3309 & 0.2784 & 44.6 & $21.4 \%$ & -0.1077 & DEU & 0.5084 & 0.3019 & 0.2601 & 48.8 & $25.7 \%$ & -0.0790 \\
\hline DNK & 0.4265 & 0.2697 & 0.2277 & 46.6 & $18.9 \%$ & -0.3068 & DNK & 0.4552 & 0.2741 & 0.2324 & 48.9 & $22.7 \%$ & -0.2002 \\
\hline EST & 0.5069 & 0.3746 & 0.3406 & 32.8 & $17.9 \%$ & -0.0975 & EST & 0.5083 & 0.3786 & 0.3434 & 32.4 & $17.9 \%$ & -0.1069 \\
\hline ESP & 0.4551 & 0.3214 & 0.32 & 29.7 & $20.7 \%$ & 0.0753 & ESP & 0.461 & 0.3302 & 0.3296 & 28.5 & $21.0 \%$ & 0.0850 \\
\hline FIN & 0.4828 & 0.2975 & 0.252 & 47.8 & $23.2 \%$ & -0.1279 & FIN & 0.4865 & 0.2998 & 0.2517 & 48.3 & $23.7 \%$ & -0.1213 \\
\hline FRA (2005) & 0.4511 & 0.2966 & 0.2809 & 37.7 & $26.2 \%$ & 0.0768 & FRA & 0.5027 & 0.3135 & 0.2845 & 43.4 & $26.5 \%$ & 0.0580 \\
\hline GRC & 0.4702 & 0.3359 & 0.3292 & 30.0 & $21.5 \%$ & 0.1342 & GRC & 0.4747 & 0.3344 & 0.3281 & 30.9 & $21.7 \%$ & 0.1389 \\
\hline GBR & 0.5061 & 0.3658 & 0.3422 & 32.4 & $14.3 \%$ & -0.3183 & GBR & 0.5445 & 0.3842 & 0.3315 & 39.1 & $18.9 \%$ & -0.1157 \\
\hline HUN (2005) & 0.5379 & 0.2893 & 0.2893 & 46.2 & $35.7 \%$ & 0.0166 & HUN & 0.5522 & 0.3378 & 0.2743 & 50.3 & $28.1 \%$ & -0.0273 \\
\hline IRL & 0.5066 & 0.3583 & 0.3117 & 38.5 & $17.5 \%$ & -0.2052 & IRL & 0.5123 & 0.3601 & 0.3146 & 38.6 & $19.5 \%$ & -0.1221 \\
\hline ISR (2005) & 0.5102 & 0.414 & 0.3683 & 27.8 & $11.4 \%$ & -0.1052 & & & & & & & \\
\hline ITA & 0.5166 & 0.3897 & 0.3386 & 34.5 & $19.5 \%$ & 0.0766 & ITA & 0.4767 & 0.3249 & 0.3248 & 31.9 & $27.7 \%$ & 0.1924 \\
\hline LUX & 0.4579 & 0.3051 & 0.2678 & 41.5 & $23.4 \%$ & 0.0347 & LUX & 0.4554 & 0.2992 & 0.2597 & 43.0 & $23.9 \%$ & 0.0378 \\
\hline NLD & 0.4671 & 0.3019 & 0.2594 & 44.5 & $21.3 \%$ & -0.044 & NDL & 0.4653 & 0.3014 & 0.2589 & 44.4 & $21.3 \%$ & -0.0443 \\
\hline NOR & 0.4516 & 0.2923 & 0.2552 & 43.5 & $20.2 \%$ & -0.1549 & NOR & 0.4711 & 0.2853 & 0.2462 & 47.7 & $23.1 \%$ & -0.1038 \\
\hline POL & 0.5515 & 0.3208 & 0.3153 & 42.8 & $33.3 \%$ & 0.1462 & POL & 0.5737 & 0.3786 & 0.3711 & 35.3 & $27.5 \%$ & 0.1019 \\
\hline SWE (2005) & 0.4503 & 0.273 & 0.2361 & 47.6 & $24.6 \%$ & -0.1285 & SWE & 0.4549 & 0.2696 & 0.2316 & 49.1 & $27.1 \%$ & -0.0521 \\
\hline SVN & 0.3994 & 0.2426 & 0.2426 & 39.3 & $28.1 \%$ & 0.0154 & SVN & 0.458 & 0.3005 & 0.2459 & 46.3 & $24.2 \%$ & -0.0643 \\
\hline USA & 0.494 & 0.4197 & 0.3766 & 23.8 & $9.8 \%$ & -0.0647 & & & & & & & \\
\hline
\end{tabular}

Note: MI=Market Income; GI=Gross Income; DI=Disposable Income; RE=Redistributive Effect; ST=Social Transfers; CC=Concentration Coefficient

Source: LIS \& EU-SILC. 